Aus der Klinik für Gastroenterologie und gastrointestinale Onkologie

(Prof. Dr. med. V. Ellenrieder)

der Medizinischen Fakultät der Universität Göttingen

\title{
Cytomegalievirusinduzierte Gastroenteritis bei chronisch-entzündlich darmerkrankten und stammzelltransplantierten Patienten: eine retrospektive Studie
}

\author{
INAUGURAL-DISSERTATION \\ zur Erlangung des Doktorgrades \\ der Medizinischen Fakultät der \\ Georg-August-Universität zu Göttingen
}

vorgelegt von

Kristin Ternes

aus

Mühlhausen

Göttingen 2020 
Dekan:

Referent/in:

Ko-Referent/in:

Datum der mündlichen Prüfung:
Prof. Dr. med. W. Brück

PD Dr. med. A. Amanzada

Prof. Dr. G. G. Wulf

25.03.2021 
Hiermit erkläre ich, die Dissertation mit dem Titel "Cytomegalievirusinduzierte Gastroenteritis bei chronisch-entzündlich darmerkrankten und stammzelltransplantierten Patienten: eine retrospektive Studie" eigenständig angefertigt und keine anderen als die von mir angegebenen Quellen und Hilfsmittel verwendet zu haben.

Göttingen, den 


\section{Inhaltsverzeichnis}

\begin{tabular}{|c|c|c|}
\hline & Abbildungsverzeichnis & II \\
\hline & Tabellenverzeichnis & III \\
\hline & Abkürzungsverzeichnis & IV \\
\hline 1 & Einleitung & 1 \\
\hline 1.1 & CMV & 1 \\
\hline 1.2 & Immunsuppression & 2 \\
\hline 1.3 & Diagnostik der CMV-Gastroenteritis & 4 \\
\hline 1.4 & Therapieoptionen der CMV-Gastroenteritis & 7 \\
\hline 1.5 & Fragestellung & 7 \\
\hline 2 & Material und Methoden & 9 \\
\hline 2.1 & Patientenkollektive & 9 \\
\hline 2.2 & Laborchemische und endoskopische Diagnostik & 11 \\
\hline 2.3 & Histologie und Immunhistochemie & 12 \\
\hline 2.4 & Serologie und PCR & 13 \\
\hline 2.5 & Statistische Analysen & 13 \\
\hline 3 & Ergebnisse & 15 \\
\hline 3.1 & Basischarakteristika der Kohorten CED und STX & 15 \\
\hline 3.1 .1 & Basischarakteristika CED-Kohorte & 15 \\
\hline 3.1 .2 & Basischarakteristika STX-Kohorte & 15 \\
\hline 3.1 .3 & Analyse nach CMV-Status der CED-Kohorte & 16 \\
\hline 3.1 .4 & Analyse nach CMV-Status der STX-Kohorte & 17 \\
\hline 3.1 .5 & Analyse nach Anzahl gleichzeitig einzunehmender Immunsuppressiva der CED-Kohorte & 18 \\
\hline 3.1 .6 & Analyse nach Anzahl gleichzeitig einzunehmender Immunsuppressiva der CED-Kohorte & 18 \\
\hline 3.2 & Diagnostik des CMV-Status & 19 \\
\hline 3.2 .1 & Diagnostische Genauigkeit des CMV-Status der CED-Kohorte & 19 \\
\hline 3.2 .2 & Diagnostische Genauigkeit des CMV-Status der STX-Kohorte & 20 \\
\hline 3.3 & Prädiktive Parameter und Risikofaktoren für eine CMV-Erkrankung & 21 \\
\hline 3.3 .1 & Prädiktive Parameter und Risikofaktoren der CED-Kohorte & 21 \\
\hline 3.3 .2 & Prädiktive Parameter und Risikofaktoren der STX-Kohorte & 24 \\
\hline 3.4 & Antivirale Therapie der CMV-Erkrankung und Ansprechrate der behandelten Patienten & 26 \\
\hline 3.4 .1 & Antivirale Therapie und Ansprechrate der CED-Kohorte & 26 \\
\hline 3.4 .2 & Antivirale Therapie und Ansprechrateder STX-Kohorte & 26 \\
\hline 4 & Diskussion & 28 \\
\hline 4.1 & $\begin{array}{l}\text { Prädiktive Parameter, Risikofaktoren und diagnostische Genauigkeit der verwendeten } \\
\text { Methoden }\end{array}$ & 28 \\
\hline 4.1 .1 & $\begin{array}{l}\text { Prädiktive Parameter, Risikofaktoren und diagnostische Genauigkeit der verwendeten } \\
\text { Methoden der CED-Kohorte }\end{array}$ & 29 \\
\hline 4.1 .2 & $\begin{array}{l}\text { Prädiktive Parameter, Risikofaktoren und diagnostische Genauigkeit der verwendeten } \\
\text { Methoden der STX-Kohorte }\end{array}$ & 30 \\
\hline 4.2 & Antivirale Therapie und therapeutisches Ansprechen & 31 \\
\hline 4.2 .1 & Antivirale Therapie und therapeutisches Ansprechen der CED-Kohorte & 31 \\
\hline 4.2 .2 & Antivirale Therapie und therapeutisches Ansprechen der STX-Kohorte & 32 \\
\hline 4.3 & Limitationen der Studie & 32 \\
\hline 5 & Zusammenfassung & 34 \\
\hline 6 & Literaturverzeichnis & 36 \\
\hline
\end{tabular}




\section{Abbildungsverzeichnis}

Abbildung 1: Therapieschema Morbus Crohn nach Krankheitsaktivität.....................................................................

Abbildung 2: Therapieschema Colitis ulcerosa nach Krankheitsaktivität...................................................................

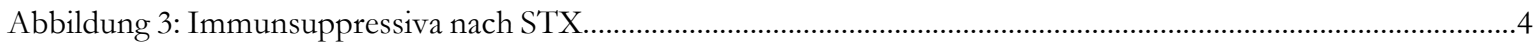

Abbildung 4: Schematische Darstellung Eulenaugenzellen im Vergleich zur normalen Zellgröße...............................6

Abbildung 5: Kollektivzusammenstellung der Kohorte der CED ..............................................................................9

Abblidung 6: Kollektivzusammenstellung der Kohorte der STX ............................................................................10

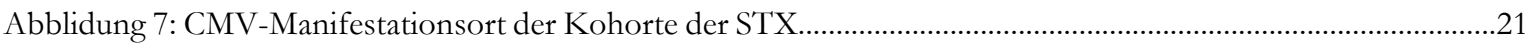

Abbildung 8: Laborchemische Parameter der CED-Kohorte dargestellt nach dem CMV-Status...........................22

Abbildung 9: ROC-Analyse von Hämoglobin, Cut-off sowie Odds ratio von Hämoglobin der CED-Kohorte ........23

Abbildung 10: ROC der täglichen Einnahme von Cortisondosis, Cut-off und Odds ratio von Cortison der CED-

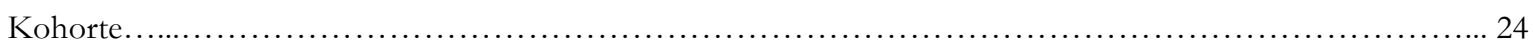

Abbildung 11: Laborchemische Parameter der STX-Kohorte dargestellt nach dem CMV-Status.............................25

Abbildung 12: Letalität der CED- und STX-Kohorte in Abhängigkeit vom CMV-Status...........................................27 


\section{Tabellenverzeichnis}

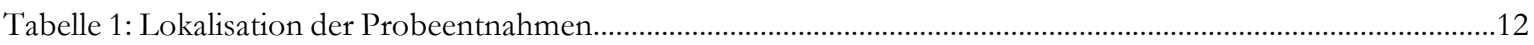

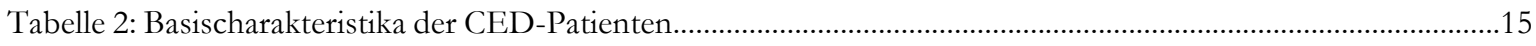

Tabelle 3: Basischarakteristika der STX-Patienten......................................................................................................16

Tabelle 4: Vergleich zwischen CMV(-)- und CMV(+)-CED-Kohorte.......................................................................17

Tabelle 5: Vergleich zwischen CMV(-)-, CMV(+)- und CMV(+)-Gastroenteritis-STX-Kohorte ..............................18

Tabelle 6: Anzahl der Immunsuppressiva bei der CED-Kohorte...............................................................................18

Tabelle 7: Anzahl der Immunsuppressiva bei der STX-Kohorte............................................................................19

Tabelle 8: Testverfahren zur Diagnosesicherung der CMV-Infektion bei der CED-Kohorte...................................19

Tabelle 9: Testverfahren zur Diagnosesicherung der CMV-Infektion bei der STX-Kohorte.....................................20 


\section{Abkürzungsverzeichnis}

\begin{tabular}{|c|c|}
\hline 5-ASA & 5-Aminosalicylate \\
\hline ALT & Alanin-Aminotransferase \\
\hline AUC & area under the curve/Fläche unter der Kurve \\
\hline BAL & Bronchioalveoläre Lavage \\
\hline CED & Chronisch-entzündliche Darmerkrankung \\
\hline $\mathrm{CNI}$ & Calcineurininhibitor \\
\hline CMV & Cytomegalievirus \\
\hline CMV (-) & Negative Cytomegalievirusinfektion \\
\hline $\mathrm{CMV}(+)$ & Positive/Reaktivierte Cytomegalievirusinfektion \\
\hline CMV-GE & Cytomegealievirus-Gastroenteritis \\
\hline СyA & Ciclosporin A \\
\hline DNA & Desoxyribonukleinsäure \\
\hline ECCO & European Crohn’s \& Colitis Organization \\
\hline E.1. & Exitus letalis \\
\hline EDTA & Ethylendiamintetraessigsäure \\
\hline Evero & Everolimus \\
\hline GvHD & graft-versus-host disease \\
\hline $\mathrm{Hb}$ & Hämoglobin \\
\hline hCMV & Humanes Cytomegalievirus \\
\hline $\mathrm{H} \& \mathrm{E}$ & Hämatoxylin-Eosin-Färbung \\
\hline HHV 5 & Humanes Herpesvirus 5 \\
\hline IHC & Immunhistochemie \\
\hline $\operatorname{IgG}$ & Immunglobulin $G$ \\
\hline IS & Immunsuppressiva \\
\hline MMF & Mycophenolatmotefil \\
\hline m-TOR & mechanistic target of rapamycin \\
\hline NPV & Negativer prädiktiver Wert \\
\hline OR & odds ratio \\
\hline PCR & Polymerase-Kettenreaktion \\
\hline PE & Probeentnahme \\
\hline PPV & Positiver prädiktiver Wert \\
\hline pp-65-AG & Phosphoprotein-65-Antigen \\
\hline $\mathrm{RP}$ & Richtig positive \\
\hline STX & Stammzelltransplantion \\
\hline Tac & Tacrolimus \\
\hline UMG & Universitätsmedizin Göttingen \\
\hline
\end{tabular}




\section{$1 \quad$ Einleitung}

Die Cytomegalievirus-(CMV)-Gastroenteritis stellt eine schwerwiegende Komplikation der Immunsuppression bei Patienten mit chronisch-entzündlichen Darmerkrankungen (CED) sowie nach allogener Stammzelltransplantation (STX) dar. Die CMV-Gastroenteritis kann mit einer erhöhten Morbidität und Mortalität vergesellschaftet sein und bedarf besonderer Aufmerksamkeit in Bezug auf Diagnostik und Behandlung (Stamminger 1997).

Zu den CED zählen die Colitis ulcerosa und der Morbus Crohn. Die Ätiologie beider Erkrankungen ist bisher nicht vollständig geklärt. Eine genetische Prädisposition konnte bei der Colitis ulcerosa sowie dem Morbus Crohn festgestellt werden. Der Morbus Crohn zeigt einen diskontinuierlichen, transmuralen Befall, der den gesamten Magen-Darm-Trakt betrifft. Die Stuhlfrequenz ist im Gegensatz zur Colitis ulcerosa nur leicht erhöht, auch Obstipation kann vorliegen. Komplikationen wie Fisteln und Abszesse können auftreten. Die Colitis ulcerosa ist gekennzeichnet durch eine stark erhöhte Stuhlfrequenz und einen kontinuierlichen Befall der Mukosa und Submukosa des Colons. Bei der Colitis ulcerosa ist in der Regel nur das Colon betroffen (Kucharzik et al. 2018; Preiß et al. 2014).

Eine STX erfolgt hauptsächlich nach Hochdosis-Chemotherapie und dient der Regeneration von Bestandteilen des Blutes und Zellen der Immunabwehr. Es kann zwischen autologer (selbst) und allogener (fremd) Stammzelltransplantation unterschieden werden. Eine autologe Transplantation erfolgt aus Zellen des Empfängers selbst, die vor der Chemotherapie entnommen werden. Bei einer allogenen Transplantation handelt es sich um eine Zellspende eines gesunden Spenders, bei dem allerdings eine Histokompatibilität vorliegen muss. Die Indikationen für eine Stammzelltransplantation sind beispielsweise Leukämien, Lymphome und das Multiple Myelom, bei denen durch die Hochdosis-Chemotherapie eine Myeloablation Voraussetzung ist. Im Anschluss können so gesunde Stammzellen transplantiert werden, um eine Heilung der zugrundeliegenden Erkrankung zu ermöglichen.

\section{$1.1 \mathrm{CMV}$}

Das humane CMV ist ein Mitglied der Familie der Herpesviridae (HHV 5). Es handelt sich um ein behülltes Desoxyribonukleinsäure (DNA)-Virus. Die Übertragung erfolgt über Körperflüssigkeiten wie Speichel, Blut oder Muttermilch.

Bezüglich der Seroprävalenz schwanken die Angaben in der Literatur zwischen 40 und $70 \%$ der Gesamtbevölkerung. Da es sich um ein Herpesvirus handelt, kann man davon ausgehen, dass 
die Prävalenz mit zunehmendem Alter steigt. Dies liegt an der steigenden Anzahl gesellschaftlicher Kontakte (Britt und Boppana 2004; de Jong et al. 1998; Goodgame 1993; Groß 2006; Korndewal et al. 2015).

Eine nachgeburtliche Erstinfektion oder Erkrankung, ob bei Kindern oder Erwachsenen mit $\mathrm{CMV}$, verläuft beim immunkompetenten Individuum meist asymptomatisch und ohne Spätschäden. Nach einer Inkubation von zwei bis sechs Wochen kann es zu unspezifischen, grippeähnlichen Symptomen kommen. In einigen Fällen kann sich ein der Mononukleose ähnliches Krankheitsbild mit Lymphadenopathie, Fieber und einer Lymphozytose manifestieren. Während der Replikationsphase kommt es vor allem in den Oberflächenepithelien der Schleimhäute zur Vermehrung des Virus und somit zum Beginn der Infektion. Das Virus persistiert daraufhin ein Leben lang latent vor allem in myeloiden Vorläuferzellen des Knochenmarks, insbesondere den Monozyten, sowie in Epithelien oder Endothelien betroffener Organe (Groß 2006; Hirsch 2010).

Unterschieden wird dabei eine Primärinfektion von einer Reaktivierung des CMV. Beide Formen können zudem problematisch beim immuninkompetenten Menschen sein. Komplikationen der Infektion richten sich dann nach den befallenen Organen und können als CMV-Erkrankungen manifest werden wie die CMV-Hepatitis, -Enzephalitis, -Pneumonie, -Retinitis oder die CMV-Gastroenteritis/Colitis (Santos et al. 2014; Vilibic-Cavlek et al. 2015).

\subsection{Immunsuppression}

Eine Immundefizienz kann verschiedene Ursachen haben. Man unterscheidet angeborene Immundefekte, verringerte T-Zellen bei Immundefizienz durch HIV oder iatrogen gewollte Immunmodulation/Immunsuppression.

Allen Ursachen ist gemeinsam, dass das Immunsystem nicht adäquat auf opportunistische Krankheitserreger reagiert, wie es auch bei einer Infektion oder Reaktivierung des CMV der Fall ist. Immundefizienz bedarf besonderer Aufmerksamkeit, wenn diese durch therapeutische Immunsuppression auftritt, da diese das Risiko einer Infektion zusätzlich im Vergleich zu Gesunden steigert (Stamminger 1997).

Von der Grundkrankheit abhängig stehen verschiedene Immunsuppressiva bzw. Immunmodulatoren als Therapieoption zur Auswahl. Die medikamentöse Therapie bei CED beispielsweise richtet sich hauptsächlich nach der Krankheitsaktivität und der Lokalisation. Nachfolgend werden in den Abbildungen (Abb.) 1 und 2 die typisch angewandten Wirkstoffe bzw. Wirkstoffgruppen entsprechend den Therapieempfehlungen der deutschen Leitlinien für Morbus Crohn und Colitis ulcerosa aufgeführt (Kucharzik et al. 2018; Preiß et al. 2014). Bis auf 
die antientzündlich wirkenden 5-Aminosalicylate haben die eingesetzten Wirkstoffe einen immunmodulierenden Effekt.
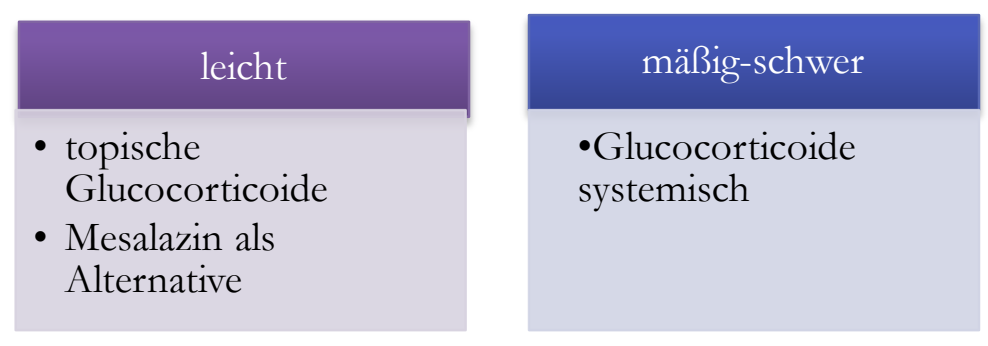

\section{Steroid-refraktär}

- TNF- $\alpha$-Antikörper

- Antimetabolite

- MTX als Alternative

TNF- $\alpha$-Antikörper: Infliximab, Adalimumab; Antimetabolite: 6-Mercaptopurin, Azathiorin; Glucocorticoide: topisch Budesonid, systemisch Prednisolon (Preiß et al. 2014).

Abb.1: Therapieschema Morbus Crohn nach Krankheitsaktivität
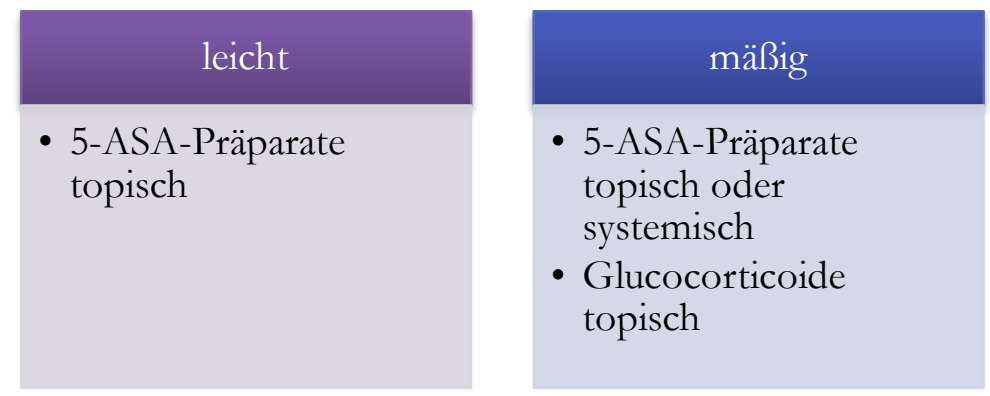

schwer

5-ASA (5-Aminosalicylate): Mesalazin, Sulfasalazin; Calcineurininhibitoren: Tacrolimus, Ciclosporin A; TNF- $\alpha$-Antikörper:Infliximab, Adalimumab; Antimetabolite: 6-Mercaptopurin, Azathiorin; Glucocorticoide: topisch: Budesonid/systemisch: Prednisolon (Kucharzik et al. 2018).

Abb.2: Therapieschema Colitis ulcerosa nach Krankheitsaktivität

In einigen Studien konnte ein Zusammenhang zwischen der Einnahme von Immunmodulatoren bei CED-Patienten und einem erhöhten Risiko einer CMV-Infektion im entzündeten Gewebe dargestellt werden (Goodgame 1993; Kishore et al. 2004; Lawlor und Moss 2010). Auch konnten Studien zeigen, dass CED-Patienten in Remission kein erhöhtes Risiko aufwiesen, an einer CMV-Colitis zu erkranken (Cottone et al. 2001; Domènech et al. 2008; Kim et al. 2010).

Die STX stellt eine kurative Therapieoption bei bestimmten malignen Erkrankungen wie bei bestimmten Leukämieformen oder den malignen Lymphomen dar. Patienten nach einer STX haben ein erhöhtes Risiko eine graft-versus-host disease (GvHD) als Komplikation der Transplantation zu erleiden. Die Prävalenz der GvHD liegt zwischen 20 und 50\% (Wagner et al. 1989).

Die GvHD kann sich ähnlich mannigfaltig äußern wie eine CMV-Erkrankung - mögliche Zielorgane stellen u.a. die Leber, die Haut sowie der Gastrointestinaltrakt dar. Dabei sind Symptome des Magen-Darm-Traktes assoziiert mit abdominellen Schmerzen, Übelkeit und Erbrechen, gastrointestinalen Blutungen und Diarrhoe. Die Gesamtmortalität nach einer STX liegt bei etwa 50\%, wobei gerade die GvHD als Risikofaktor gilt (Ross et al 2008). Um das 
Risiko einer Abstoßungsreaktion zu verringern, wird eine Therapie mit immunsuppressiven Wirkstoffen wie Cyclosporin A (CyA), Tacrolimus, Mycophenolatmofetil (MMF) oder Methotrexat (MTX) durchgeführt.

Ein zweiter Risikofaktor für eine erhöhte Gesamtmortalität stellt die CMV-Erkrankung nach einer STX unter immunsuppressiven Bedingungen dar. Diese kann gerade im ersten Jahr nach einer Transplantation bei bis zu 25\% aller STX-Patienten auftreten. Dabei manifestiert sich eine CMV-Gastroenteritis bei bis zu 10\% dieser Patienten. Eine zusätzliche CMV-Erkrankung kann die Mortalitätsrate der STX-Patienten auf bis zu 80\% ansteigen lassen (Roberts et al. 2010).

Nachfolgend werden in Abb. 3 immunsuppressive Medikamente dargestellt, die nach einer STX zum Einsatz kommen können.

\section{Immunsuppressiva nach STX}

- Ciclosporin A (CyA) als Calcineurininhibitor

- Tacrolimus als Calcineurininhibitor

- Sirolimus als mTOR Inhibitor

- Mycophenolat-Motefil (MMF)

- Biologicals

Abb. 3: Immunsuppressiva nach STX

\subsection{Diagnostik der CMV-Gastroenteritis}

Wie bereits erwähnt, kann es im Rahmen einer CMV-Infektion zu Lymphknotenschwellungen, Myalgien und Fieber kommen. Eine Infektion oder eine Reaktivierung bieten mehrere Möglichkeiten des Nachweises. An erster Stelle (1) steht die Serumdiagnostik, gefolgt von nichtinvasiver Diagnostik (2) in Form von Bildgebung oder Stuhltest. An dritter und letzter Stelle kann invasive Diagnostik (3) z. B. Bronchoskopien, Endoskopien und Liquorpunktionen erfolgen.

(1) Laborchemisch können zumeist eine Thrombozytopenie und eine Anämie nachgewiesen werden (Groß 2006; Stamminger 1997). Die Serumdiagnostik wird ergänzt durch die serologische Bestimmung von IgM, IgG, CMV-DNA und bei Bedarf pp-65-Ag.

Das IgM ist das erste Immunglobulin, das bei einer Infektion nachweisbar wird - so auch bei einer CMV-Infektion (Müller 2006; Groß 2006). Zu berücksichtigen ist einerseits, dass ein 
negativer Titer wegen möglicher Inkubationszeit keine Infektion ausschließt, andererseits eine IgM-Persistenz, d.h. ein dauerhaft hoher IgM-Titer, nicht immer für eine Reaktivierung spricht. Das IgG erscheint nach dem Immunglobulinklassenwechsel und bleibt den Rest des Lebens als ein Art Gedächtnis des Immunsystems bestehen. Kommt es zu einer Reaktivierung der Cytomegalie, steigt das IgG eventuell wieder an.

Noch viel aussagekräftiger als der Immunglobulin-Nachweis ist die Bestimmung viraler DNA in Leukozyten des Blutes mit Hilfe der Polymerase-Kettenreaktion (PCR)-Untersuchung. Bei Nachweis von viraler DNA kann von einer Infektion ausgegangen werden und sie spiegelt im steigenden Niveau die Schwere der CMV-Infektion wieder (Groß 2006).

Das pp-65-Ag kann in Lymphozyten aus Vollblut durch Immunfluoreszenzverfahren nachgewiesen werden und stellt einen Aktivitätsmarker einer CMV-Reaktivierung dar. Dieses wird nicht grundsätzlich empfohlen, da die Sensitivität und Spezifität sich in der Praxis nicht als ausreichend erwiesen haben (Hirsch 2010).

(2) Als nächstes sollte bei dringendem Verdacht auf eine Organmanifestation erweiterte nichtinvasive Diagnostik erfolgen. Diese umfasst z.B. Röntgen-Thorax-Aufnahmen bei Verdacht auf eine CMV-Pneumonie, eine Fundusspiegelung bei CMV-Retinitis oder einen Stuhltest bei dringendem Verdacht auf eine CMV-Kolitis. Dieser Stuhltest wird ebenfalls mittels PCR auf CMV-DNA untersucht.

(3) Invasive Verfahren sollten erst zum Schluss der Diagnostik erfolgen, wenn sich die anderen Nachweisverfahren nicht als zielführend erweisen konnten. Gerade die Unterscheidung bei STX-Patienten zwischen GvHD und CMV-Colitis kann invasive Verfahren notwendig machen.

Bei diesen Verfahren wird Probematerial vermutlich betroffener Organe entnommen. Es kann ein Nachweis in Form von histologischer Betrachtung von Schnitten des Gewebes durch die Pathologie erfolgen. Diese Schnitte werden eingefärbt mit Hämatoxylin und Eosin (H\&E) und unter dem Mikroskop betrachtet. Dabei können einzelne vergrößerte Zellen, welche durch einen zytopathischen Effekt entstehen, mit intranukleären eosinophilen Einschlusskörpern, sogenannten Eulenaugenzellen, nachgewiesen werden, was auch im Namen Cytomegalie oder Einschlusskörperchenkrankheit verdeutlicht wird (Hirsch 2010). Diese Eulenaugenzellen sind spezifisch für eine CMV-Infektion. 

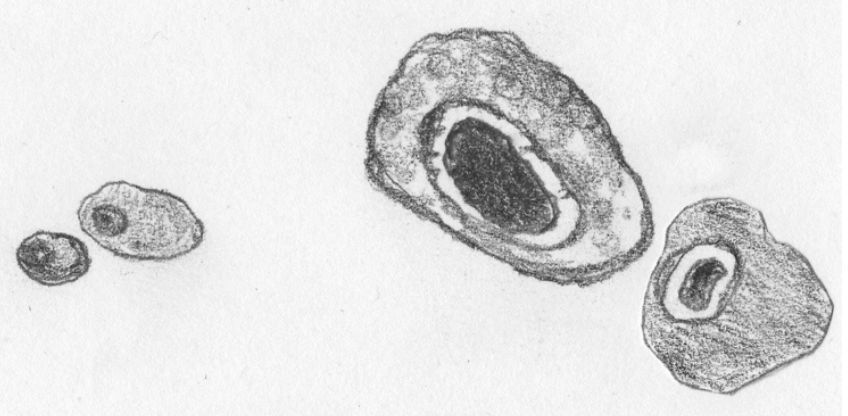

Abb. 4: Schematische Darstellung Eulenaugenzellen im Vergleich zur normalen Zellgröße

Eine weitere Möglichkeit zum Nachweis bietet die Immunhistochemie (IHC). Mit Hilfe einer Antikörperfärbung, die sich gegen Antigene von Hüllproteinen des CMV richtet und diese sichtbar macht, kann eine CMV-Infektion nachgewiesen werden (Fegeler und Herbst 2004).

Darüber hinaus kann auch eine PCR des Probematerials betroffener Organe den Nachweis einer Infektion erbringen.

Ein einheitlicher Goldstandard zur Diagnostik einer gewebeinvasiven CMV-Infektion konnte bisher nicht klar definiert werden. Einige Studien präferieren die Diagnosestellung eindeutig durch die Histologie und IHC aus den Gewebeproben. Bei Patienten mit Colitis ulcerosa konnte so der Nachweis des CMV von 0,5\% für die Histologie allein auf 20 bis $40 \%$ gesteigert werden, wenn die Histologie um die IHC erweitert wurde (Domènech et al. 2008; Cottone et al. 2001; Kojima et al. 2006; Kambham et al. 2004). Allerdings scheint eine reine PCR-Diagnostik aus Gewebeproben in manchen Studien schlechter auszufallen (38\%) als der Nachweis im Blut (60\%) (Pofelski et al. 2007; Yoshino et al. 2007).

In anderen Studien, die Morbus-Crohn-Patienten betrachteten, konnte die IHC keinen positiven Nachweis erbringen bezüglich einer CMV-Infektion. Die PCR aus Probeentnahmen (PE) zeigte jedoch auch nur eine geringe Trefferquote (Kim et al. 2010).

Die zugrundeliegende Erkrankung spielt bei einer CMV-Infektion eine besondere Rolle. So scheinen Patienten mit einer steroid-refraktären Colitis ulcerosa oder Morbus Crohn ein deutlich erhöhtes Risiko zu haben, an einer CMV-Infektion zu erkranken (Nakase et al. 2010; McCurdy et al. 2015).

Die European Crohn's \& Colitis Organization (ECCO) empfiehlt zur Diagnostik einer gastrointestinalen CMV-Erkrankung zu den histologischen Verfahren auch eine PCR-Untersuchung aus Gewebeproben durchzuführen (Rahier et al. 2009).

Eine frühe Identifikation einer CMV-Erkrankung bei CED- und STX-Patienten ist von entscheidender Bedeutung. Eine manifeste CMV-Infektion kann sich klinisch ähnlich äußern wie ein akuter Schub bei der CED oder einer GvHD bei STX. Die Therapie wäre aber 
grundsätzlich unterschiedlich. Eine nicht korrekt durchgeführte Diagnostik und ein verzögerter Beginn der Therapie verschlechtert maßgeblich die Prognose der Patienten.

\subsection{Therapieoptionen der CMV-Gastroenteritis}

Bei immunkompetenten Individuen wird in der Regel keine Therapie der CMV-Infektion empfohlen, da es zu keiner schwerwiegenden Erkrankung kommt. Bei immunsuppremierten Individuen sollte jedoch zeitig eine Therapie in Erwägung gezogen werden, da es zu schwerer Symptomatik mit Komplikationen bis hin zum Tod kommen kann (Stamminger 1997). Dazu stehen aktuell zwei spezifische Medikamente mit Zulassung zur Verfügung. Als Virostatikum ist das Ganciclovir als intravenöser und Valganciclovir als enteral verabreichbarer Wirkstoff zu nennen. Beide Wirkstoffe inhibieren die DNA-Polymerase und werden über die Leber verstoffwechselt. Ganciclovir weist viele Nebenwirkungen auf wie z.B. Parästhesien, Blutbildveränderungen oder Übelkeit und Erbrechen, da es auf alle Zellen des Körpers wirkt, nicht nur auf CMV-infizierte Zellen (McGavin und Goa 2001; Cvetkovic und Wellington 2005). Aufgrund dieser unerwünschten Begleiterscheinungen wird im deutschsprachigen Raum keine Prophylaxe der CMV-Infektion/Reaktivierung bei STX-Patienten durchgeführt.

\section{$1.5 \quad$ Fragestellung}

Bei immunsupprimierten Patienten scheint die CMV-Infektion mit einer signifikant erhöhten Morbidität und Mortalität assoziiert zu sein.

Daher sollte in dieser retrospektiven Dissertationsarbeit bei Patienten mit CED und bei Patienten mit Z. n. allogener STX folgende Fragestellungen untersucht werden:

1. Stellt die PCR das Mittel der Wahl zur Diagnosesicherung von CMV-Gastroenteritis aus intestinalen Gewebeproben dar?

2. Zieht die Behandlung mit Glucocorticoiden ein erhöhtes Risiko nach sich, an CMV zu erkranken?

3. Stellen Immunsuppressiva einen Risikofaktor für CMV-Erkrankung dar?

4. Gibt es Laborparameter, die auf eine CMV-Erkrankung hinweisen?

5. Kann die Endoskopie zur Diagnosefindung beitragen? 
6. Nimmt die Mortalität durch eine zusätzliche CMV-Erkrankung in den untersuchten Kohorten zu?

7. Hat die steigende Anzahl der Immunsuppressiva einen Einfluss auf die Wahrscheinlichkeit einer CMV-Erkrankung oder CMV-Reaktivierung? 


\section{Material und Methoden}

\subsection{Patientenkollektive}

Für die Studie wurden die Daten von Patienten mit einer CED-Diagnose nach dem International Classification of Disease (ICD 10) mit der Codierung K50 für Morbus Crohn (CD) und K51 für Colitis ulcerosa (UC) gesammelt, die in der Klinik für Gastroenterologie und gastrointestinale Onkologie vorstellig waren.

Es erfolgte die Auswertung der Daten von Patienten, welche sich zwischen Januar 2005 und Dezember 2016 in der UMG in Behandlung befanden. 902 Patienten mit der Hauptdiagnose CED konnten identifiziert werden. Nach Ausschluss von CED-Patienten aufgrund von unvollständiger Krankengeschichte, unvollständige/keine Suche oder Seronegativität bezüglich CMV, konnten 105 Patienten in die Studie eingeschlossen werden (Abb. 5). 85 Patienten wurden in eine $\mathrm{CMV}(-)$ - und 20 Patienten in eine $\mathrm{CMV}(+)$-Gruppe unterteilt. CMV(-) wird seropositiven (d.h. IgG positiv) Patienten zugeordnet, die keine CMV Reaktivierung aufweisen. $\mathrm{CMV}(+)$ definiert sich als Neuinfektion, Übertragung oder als Reaktivierung seropositiver IgG-Träger.

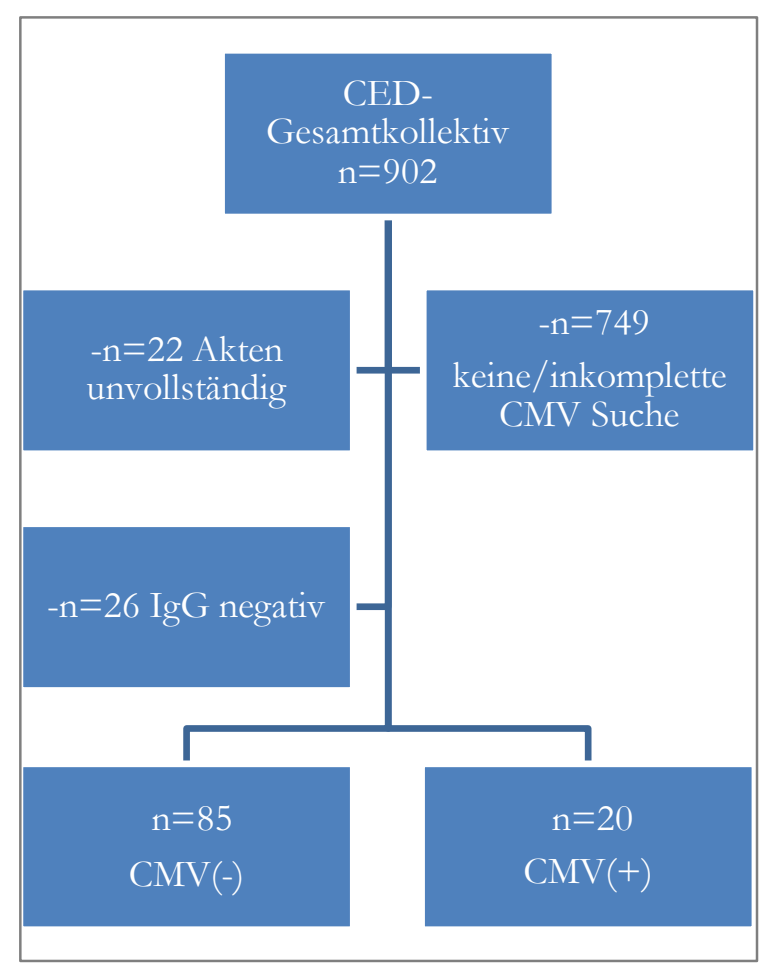

Abb. 5: Kollektivzusammenstellung der Kohorte der CED 
Die Diagnostik einer CED basiert dabei auf klinischen, laborchemischen, endoskopischen, radiologischen und histopathologischen Gesichtspunkten.

Bei allen Patienten wurden folgende Daten gesammelt: Demographie, Laborergebnisse, endoskopische Befunde, pathologische oder mikrobiologische Befunde sowie die Medikamenteneinnahme einschließlich antiviraler Therapie.

Die untersuchten Proben der STX-Patienten entstammen alle der Klinik für Gastroenterologie und gastrointestinale Onkologie. Behandelt wurden diese Patienten in der Klinik für Hämatologie und Medizinische Onkologie der UMG. Zur Dokumentation der endoskopischen Untersuchungen wird die Software WinData ${ }^{\circledR}$ von E\&L medicalsystems GmbH, Erlangen, Deutschland benutzt. Unter dem Begriff „GvHD“ und/oder „Stammzelltransplantation“ wurden die Daten von Patienten mit STX gesammelt.

Die STX-Kohorte umfasste initial 217 Patienten nach STX, die sich nach Abzügen durch unvollständige Krankengeschichte und Seronegativität auf 120 Patienten reduzierte (Abb. 6).

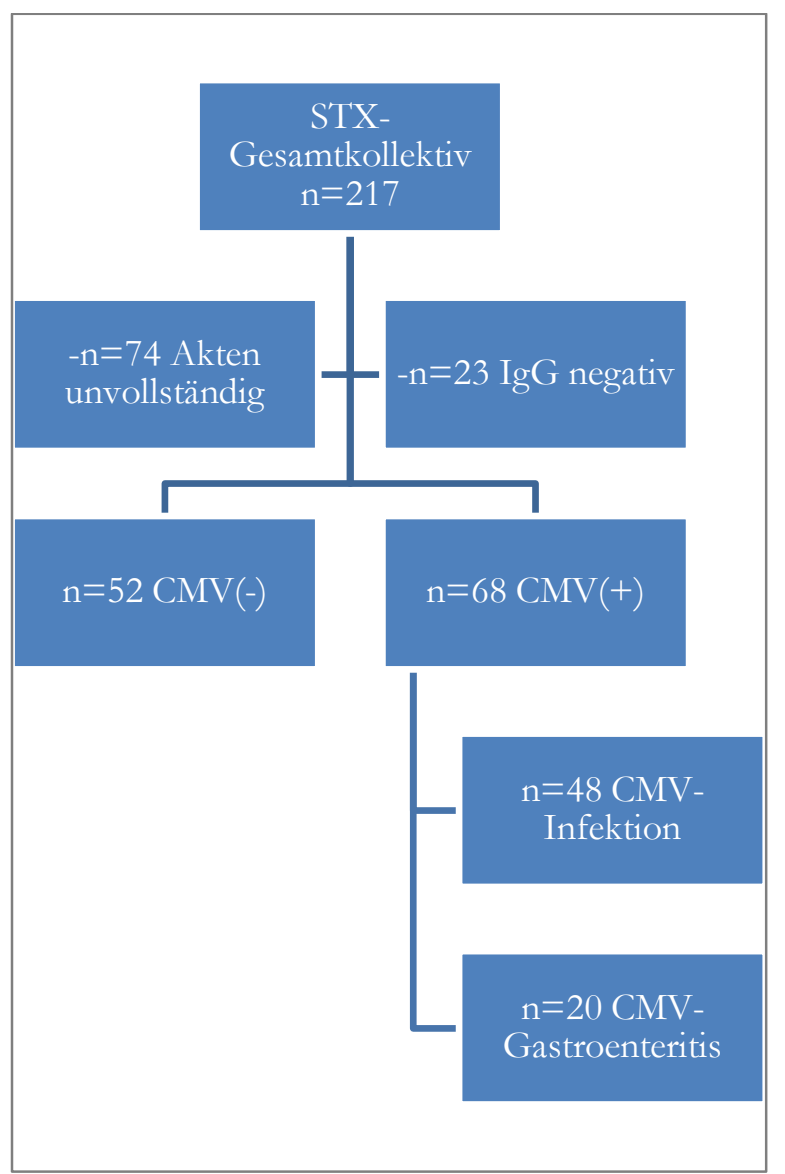

Abb. 6 Kollektivzusammenstellung der Kohorte der STX

Bei allen 225 in dieser Studie eingeschlossenen Patienten galt zunächst die Voraussetzung, dass der Serostatus bezüglich des Vorhandenseins oder Nicht-Vorhandenseins von IgM- oder IgG-Antikörper bekannt war. Als CMV(-)-Patienten wurden solche definiert, die $\operatorname{IgG}(+)$ waren, 
d.h. es fand in der Vergangenheit eine Primärinfektion unbekannten oder bekannten Zeitpunktes statt, die aber keine Aktivität bezüglich des CMV-DNA Nachweises zeigten, weder im Serum noch in Probebiopsien.

Als CMV(+)-Patienten wurden im Umkehrschluss solche definiert, welche nicht nur positive IgM- oder IgG-Antikörper, sondern auch andere Aktivitätsparameter aufwiesen. Der Nachweis von einer stattfindenden Replikation des viralen Genoms kann definitionsgemäß entweder mittels quantitativer PCR aus gewonnenem Serum oder Probebiopsien, mit immunhistochemischen Färbungen oder in Form von histologischen Merkmalen, wie dem Nachweis von Eulenaugenzellen, durchgeführt werden.

In der quantitativen PCR wird eine aktive Replikation der CMV-DNA nach Primärinfektion oder Reaktivierung dabei als Cytomegalie-Viruslast oder Cytomegalie-Virämie bezeichnet. Ihr Nachweis gilt als diagnostischer Standard und Empfehlung. In dieser Arbeit wurde nicht allein der Serumnachweis einer Cytomegalie-Virämie, sondern auch der Nachweis von CMV-DNA aus Probebiopsien als beweisend für eine aktive CMV-Erkrankung angenommen.

Die Einnahme von Immunsuppressiva wurde mittels Einordnung in entsprechende Wirkstoffgruppen in die statistischen Analysen einbezogen. Gleichzeitig wurde der Frage nachgegangen, ob oder bis zu wie viele Immunsuppressiva jeder Patient erhielt.

Diese retrospektive Studie wurde von der Ethikkommission der Universitätsmedizin Göttingen (UMG) geprüft und zugelassen (DOK_211_2015). Die Erhebung der Daten erfolgte aus archivierten Patientenakten und digitalen Patientendaten in Form von Befunden aus dem Institut für Pathologie der UMG und dem Institut der Medizinischen Mikrobiologie der UMG sowie aus Arztbriefen und Befunden der klinischen Chemie. Der Datenschutz wurde zu jeder Zeit beachtet und eingehalten.

\subsection{Laborchemische und endoskopische Diagnostik}

In der statistischen Analyse beider Kohorten wurden vorhandene Laborergebnisse bezüglich Hämoglobin, Thrombozytenzahl, Leukozytenzahl, dem C-reaktiven Protein (CRP), Kreatinin, Alanin-Aminotransferase (ALT), Albumin und Protein untersucht.

Die Gewebebiopsien erfolgten in der Klinik für Gastroenterologie der Universitätsmedizin Göttingen mit Hilfe konventioneller endoskopischer Instrumente (Olympus Co, Ltd, Tokyo, Japan). Diese Biopsien gewann man aus unterschiedlichen Organen des Gastrointestinaltraktes. In der Regel entnahm man diese aus dem Rand verdächtiger Läsionen. 
Eine Fixierung der Biopsieproben für eine H\&E- sowie IHC-Untersuchung fand in 10\%iger Formalin-Lösung statt. Für die quantitative PCR-Untersuchung versendete man das Material in 0,9\%iger NaCl-Lösung.

Insgesamt konnten 70 Biopsie-Serien bei der CED-Kohorte und 110 Biopsie-Serien bei der STX-Kohorte während endoskopischer Untersuchungen entnommen werden. Als Serien sind mehrere Probeentnahmen aus unterschiedlichen Lokalisationen zu verstehen (Tab. 1).

Zusätzlich erfolgten in der Kohorte der STX auch andere Probeentnahmen zur Diagnostik einer möglichen CMV-Infektion z. B. in Form von BAL oder Liquorpunktionen.

Tab. 1 Lokalisation der Probeentnahmen

\begin{tabular}{|lcc|}
\hline Lokalisation & PE-Serien CED & PE-Serien STX \\
\hline Ösophagus & 0 & N \\
\hline Gaster & 5 & 2 \\
\hline Duodenum & 3 & 78 \\
\hline Jejunum & 0 & 43 \\
\hline Ileum & 9 & 2 \\
\hline Coecum & 6 & 1 \\
\hline Colon & 55 & 6 \\
\hline Sigma & 51 & 31 \\
\hline Rectum & 42 & 41 \\
\hline Ohne Angabe & 33 & 0 \\
\hline Anastomose & 2 & 0 \\
\hline Polypen & 2 & \\
\hline PE: Probeentnahme & & 0 \\
\hline
\end{tabular}

\subsection{Histologie und Immunhistochemie}

Die Untersuchung und Auswertung der entnommenen Gewebeproben erfolgte durch Mitarbeiter im Institut der Pathologie der UMG mittels H\&E und IHC. Die Proben der 
CED-Kohorte untersuchte man bezüglich der Fragestellung nach einer CMV-Infektion. Die Proben der STX-Kohorte betrachtete man nach dem Gesichtspunkt einer möglichen CMV-Infektion sowie differentialdiagnostisch einer GvHD. Dazu übersandte man der Pathologie das Probematerial in 10\%iger Formalin-Lösung. Insgesamt wurden 103 PE-Serien mit der Fragestellung einer CMV an das Institut für Pathologie verschickt.

Die IHC-Methode bedient sich Anti-CMV-monoklonaler Maus-Antikörper wie DDG9 und CCH2 (Dako, Code GA752, Denmark). Die IHC erfolgte gemäß den Herstellerangaben.

\subsection{Serologie und PCR}

Die serologische Untersuchung führten Mitarbeiter des Instituts der Medizinischen Mikrobiologie der UMG durch. Alle in die Studie eingeschlossenen 225 Patienten beider Kohorten prüfte man serologisch auf IgM-/IgG-Status und mögliche CMV-DNA durch quantitative PCR im Serum.

Zusätzlich wurden 162 Proben aus gastrointestinalen Biopsien endoskopischer Läsionen in 0,9\%iger NaCl-Lösung übersandt und auf CMV-DNA-Nachweis im entnommenen Gewebe getestet.

Die Extraktion der DNA für die PCR-Untersuchung aus den gewonnen Darmbiopsien erfolgte im Institut für Medizinische Mikrobiologie der UMG mit dem MagNA Pure LC-Gesamtnucleinsäure-Isolierungskit (Roche Diagnostics, Mannheim, Deutschland) unter Verwendung des MagNA Pure LC 2.0-Instruments gemäß den Anweisungen des Herstellers.

Die gereinigte DNA wurde in einem Volumen von $200 \mu$ l eluiert und $10 \mu \mathrm{l}$ davon wurden für die quantitative Real-Time-PCR-Analyse mit dem RealStar CMV PCR Kit 1.2 (Altona Diagnostics, Hamburg, Deutschland) verwendet, welches für die diagnostische Verwendung lizenziert ist. Externe positive Kontrollen im Bereich von 10 bis $10^{4}$ CMV-Einheiten und ein internes heterologes Amplifikationssystem waren vorhanden, um die Nachweisgrenze, die Pathogenbelastung und eine mögliche PCR-Hemmung zu bestimmen. Die Spezifität des Assays wird durch eine Oligonukleotidsonde gewährleistet, die ausschließlich an das amplifizierte Produkt bindet.

\subsection{Statistische Analysen}

Die Datenerfassung gelang mit Hilfe von Excel ${ }^{\circledR}$ von Microsoft Office. Die Patienten konnten in jeweilige Gruppen nach Grundkrankheit und CMV-Status eingeteilt werden. Patienten mit 
fehlenden Daten wurden aus der Analyse ausgeschlossen. Daraus ergaben sich teilweise unterschiedliche Fallzahlen.

Die Daten wurden zunächst mit Hilfe deskriptiver Methoden ausgewertet. Dabei kamen Tabellen, Diagramme und Parameter zum Einsatz.

Zunächst erfolgte die Festlegung der Basischarakteristika der eingeschlossenen Patientengruppen wie Alter, Geschlecht, medikamentöse Therapie und Grundkrankheit. Die Häufigkeitsverteilungen werden in Anzahl und Prozent gezeigt. Bei der Angabe des Alters fand zusätzlich die Berechnung des Mittelwertes statt.

Die Analyse der erhobenen Daten erfolgte anschließend mit Hilfe der Mitarbeiter des Instituts für Medizinische Statistik der UMG. Dazu fanden die Programme STATISTICA 13.3 und SPSS Client 25.0 von IBM Verwendung.

Der exakte Fischer-Test oder Chi-Quadrat-Test zur Hypothesentestung kam zur Anwendung, wobei die statistische Signifikanzmit einem p-Wert von 0,05 festgelegt wurde.

Um eine Alphafehler-Kumulierung bei scheinbar signifikanten $\mathrm{p}$-Werten entgegenzuwirken wird eine Bonferroni-Korrektur durchgeführt - diese sind mit einem * markiert. Bei der Kohorte der CED handelte es sich dabei um den Faktor 16, bei der Kohorte der STX um den Faktor 15. Um die diagnostische Richtigkeit der These bezüglich der Cortisondosis oder des Hämoglobinwertes zu bestätigen bezüglich eines Zusammenhangs zur CMV-Infektion kamen Receiver-Operating-Characteristic-Kurve (ROC-Kurven) zum Einsatz (DeLong et al. 1988). Diese Analysen und die Darstellung gelang mit GraphPad Prism 5.

Die einzelnen diagnostischen Schritte zur Bestimmung, ob eine CMV-Gastroenteritis vorliegt, standen in dieser Arbeit zum Vergleich. Die Sensitivitäten und Spezifitäten berechnen sich mit Hilfe der Vierfeldertafel. Eingeschlossen wurden die Virämie aus Serummaterial, histologische und immunhistochemische pathologische Begutachtung und die PCR aus PE. Die Prävalenz gilt zu berücksichtigen, um die Validität zu gewährleisten. Die Prävalenz der CMV betrug in der Kohorte der CED 15\%, wobei $\mathrm{n}=20 \mathrm{CMV}(+), \mathrm{n}=85 \mathrm{CMV}(-)$ und $\mathrm{n}=26 \mathrm{IgG}(-)$ und in der Kohorte der STX 49\%, wobei $n=68 \mathrm{CMV}(+), n=52 \mathrm{CMV}(-)$ und $n=23 \operatorname{IgG}(-)$. Die Berechnungen folgten nach dem Schema:

Sensitivität

$$
\mathrm{SEN}=\mathrm{A} /(\mathrm{A}+\mathrm{C})
$$

Spezifität

$$
\mathrm{SPE}=\mathrm{D} /(\mathrm{B}+\mathrm{D})
$$

Positiv prädiktiver Wert $\mathrm{PPV}=\mathrm{A} /(\mathrm{A}+\mathrm{B})$

Negativ prädiktiver Wert $\mathrm{NPV}=\mathrm{D} /(\mathrm{C}+\mathrm{D})$

Wobei: $\mathrm{A}=$ Richtig positive, $\mathrm{B}=$ Falsch positive, $\mathrm{C}=$ Falsch negative, $\mathrm{D}=$ Richtig negative.

In Verbindung mit dem klinischen Bild aus den typischen Symptomen wie Fieber, Schmerzen und Diarrhoe galt die Diagnose einer CMV-Erkrankung bei Nachweis einer CMV-Infektion bzw. -Reaktivierung, unabhängig vom Typ des Diagnoseverfahrens. 


\section{Ergebnisse}

\subsection{Basischarakteristika der Kohorten CED und STX}

\subsubsection{Basischarakteristika der CED-Kohorte}

In der Tabelle 2 sind die Basisdaten der 105 CED-Patienten zusammengefasst. Die Daten wurden aufgeschlüsselt nach Alter, Geschlecht und Anzahl der jeweiligen immunsuppressiven Medikamente. 57 Patienten der CED-Kohorte waren an einer Colitis ulcerosa und 48 Patienten an einer Morbus Crohn erkrankt. Das Geschlechterverhältnis war nahezu gleich und das mittlere Alter belief sich auf 42,5 Jahre. In der Endoskopie fanden sich bei insgesamt 51 Patienten Ulcerationen. 26 Patienten erhielten eine Mono-Therapie, 38 eine Duale- und 14 eine Triple-Therapie.

Tab. 2 Basischarakteristika der CED-Patienten

\begin{tabular}{|lc|}
$\begin{array}{l}\text { CED-Kohorte } \\
\text { (n=105) }\end{array}$ & $57(54,3)$ \\
\hline $\begin{array}{l}\text { Colitis ulcerosa n (\%) } \\
\text { Morbus Crohn n (\%) }\end{array}$ & $48(45,7)$ \\
Geschlecht (m/w) n (\%) & $52 / 53(49,5 / 50,5)$ \\
& \\
Alter (x, IQR) & $42,5(17-77)$ \\
& \\
Ulcerationen & $51(48,6)$ \\
& \\
Medikation n (\%) & $58(55,2)$ \\
Glucocorticoide & $13(12,4)$ \\
Immunsuppressiva & $29(27,6)$ \\
Biologika & $23(21,9)$ \\
Antimetabolite & $35(33,3)$ \\
5-Aminosalicylate & $26(24,8)$ \\
Mono-Therapie & $38(36,2)$ \\
Duale-Therapie & $14(13,3)$ \\
Triple-Therapie & \\
\hline \hline Immunsuppressiva (Calcineurininhibitoren: Tacrolimus, Ciclosporin A), \\
Biologika [(TNF- $\alpha$--Inhibitoren: Infliximab, Adalimumab) Vedolizumab], \\
Antimetabolite (Metothrexat, 6-Mercaptopurin/Azathioprin), \\
5-Aminosalicylate (Mesalazin, Sulfasalazin) \\
\hline
\end{tabular}

\subsubsection{Basischarakteristika der STX-Kohorte}

In der Tabelle 3 zeigt sich die Zusammenfassung der Basisdaten von 120 STX-Patienten. Die Daten entsprechen Alter, Geschlecht und Anzahl der jeweiligen immunsuppressiven Medikamente. 72 Patienten waren männlich und 48 Patienten weiblich. Das Durchschnittsalter 
war 52,8 Jahre. Es erhielten 83 Patienten Glucocorticoide, zwölf Patienten Biologika und ein Patient ein Antimetabolit. Drei Patienten erhielten zum Betrachtungszeitpunkt Thalidomid. 19 Patienten erhielten eine Mono-Therapie, 57 eine Duale und 29 eine Triple-Therapie.

Tab. 3 Basischarakteristika der STX-Patienten

\begin{tabular}{|lc|}
\hline $\begin{array}{l}\text { STX-Kohorte } \\
(\mathrm{n}=120)\end{array}$ & $72 / 48(60 / 40)$ \\
\hline Geschlecht (m/w) n (\%) & $52,8(17-77)$ \\
& \\
& \\
Medikation n (\%) & \\
Glucocorticoide & $83(69,1)$ \\
Calcineurininhibitoren & $104(86,7)$ \\
m-Tor Inhibitoren & $1(0,8)$ \\
MMF & $43(35,8)$ \\
Biologika & $12(10)$ \\
Antimetabolite & $1(0,8)$ \\
Andere & $3(2,5)$ \\
Mono-Therapie & $19(15,8)$ \\
Duale-Therapie & $57(47,5)$ \\
Triple-Therapie & $29(24,2)$ \\
\hline \hline Immunsuppressiva (Calcineurininhibitoren: Tacrolimus, Ciclosporin A; \\
m-TOR Inhibitoren: Everolimus, Sirolimus; Mycophenolatmotefil)); \\
Biologika: Rituximab, Alemtuzumab; Antimetabolite (Metothrexat, \\
6-Mercaptopurin/Azathioprin); Andere (Thalidomid)
\end{tabular}

\subsubsection{Analyse nach CMV-Status der CED-Kohorte}

Die Tabelle 4 stellt die Daten der CED-Patienten getrennt nach CMV-Status dar. Zwischen CMV(-)- und CMV(+)-Gruppe konnte keine signifikante Unterschiede hinsichtlich der Erkrankungsentität, Geschlecht, Alter, endoskopisches Nachweis von Ulcerationen, medikamentöse Therapie mit Biologika, Antimetabolite und 5-Aminosalicylate festgestellt werden.

Beide Gruppen unterschieden sich signifikant hinsichtlich einer medikamentösen Therapie mit Glucocorticoide $(p=0,04)$ und Immunsuppressiva $(p=0,002)$. Eine Therapie mit Glucocorticoiden erhöhte das Risiko an einer CMV zu erkranken um 6,1fach und eine Therapie mit Immunsuppressiva um 16,6fach. 
Tab. 4 Vergleich zwischen CMV(-)- und CMV(+)-CED-Kohorte

\begin{tabular}{|c|c|c|c|c|}
\hline $\begin{array}{l}\text { CED } \\
\mathrm{n}=105\end{array}$ & $\begin{array}{c}\text { CMV(-) } \\
n=85\end{array}$ & $\begin{array}{c}\mathrm{CMV}(+) \\
\mathrm{n}=20\end{array}$ & $\begin{array}{c}\text { OR } \\
95 \% \mathrm{CI}\end{array}$ & p-Wert \\
\hline Colitis Ulcerosa n $(\%)$ & $42(49)$ & $15(75)$ & & 0,6 \\
\hline Morbus Crohn n (\%) & $43(51)$ & $5(25)$ & & \\
\hline $\begin{array}{l}\text { Geschlecht }(\mathrm{m} / \mathrm{w}) \mathrm{n} \\
(\%)\end{array}$ & $\begin{array}{r}41 / 44 \\
(48 / 52)\end{array}$ & $\begin{array}{c}11 / 9 \\
(55 / 45)\end{array}$ & & 0,83 \\
\hline $\operatorname{Alter}(\bar{x}, I Q R)$ & $39,5(17-77)$ & $45,6(18-73)$ & & 0,13 \\
\hline Ulcerationen & $36(42)$ & $15(75)$ & & 0,16 \\
\hline \multicolumn{5}{|l|}{ Medikation n (\%) } \\
\hline Glucocorticoide & $41(48)$ & $17(85)$ & $6.1(1.7-22.3)$ & $0,04 *$ \\
\hline Immunsuppressiva & $4(5)$ & $9(30)$ & $16.6(4.4-63.0)$ & $0,002^{*}$ \\
\hline Biologika & $25(29)$ & $4(20)$ & & 0,57 \\
\hline Antimetabolite & $20(24)$ & $3(15)$ & & 0,55 \\
\hline 5-Aminosalicylate & $30(35)$ & $5(25)$ & & 0,37 \\
\hline
\end{tabular}

\subsubsection{Analyse nach CMV-Status der STX-Kohorte}

Die Tabelle 5 stellt die Daten der STX-Patienten getrennt nach CMV-Status dar. Zwischen der CMV(-)-, CMV(+)- und CMV(+)-GE-Gruppe zeigte sich keine signifikanten Unterschiede hinsichtlich Geschlecht, Alter, GvHD und medikamentöse Therapie mit Glucocorticoide, Immunsuppressiva, MMF und andere eingesetzten Wirkstoffen.

Bei Patienten der CMV(+)-GE-Gruppe kam im Vergleich $\mathrm{zu}$ den Patienten der CMV(-)-Gruppe ein signifikanter Unterschied hinsichtlich des Nachweises endoskopische Ulcerationen $(p=0,007)$ zum Vorschein. Patienten mit endoskopischem Nachweis einer Ulceration erkrankten 7,8fach häufiger an einer CMV als Patienten ohne endoskopische Nachweis einer Ulceration. 
Tab. 5 Vergleich zwischen CMV(-)-, CMV(+)- und CMV(+)-Gastroenteritis-STX-Kohorte

\begin{tabular}{|c|c|c|c|c|c|}
\hline $\begin{array}{l}\text { STX } \\
n=120\end{array}$ & $\begin{array}{c}\text { A } \\
\text { CMV(-) } \\
n=52\end{array}$ & $\begin{array}{c}\text { B } \\
\text { CMV (+) } \\
\text { n=48 }\end{array}$ & $\begin{array}{c}\mathrm{C} \\
\mathrm{CMV}(+)-\mathrm{GE} \\
\mathrm{n}=20\end{array}$ & $\begin{array}{l}\text { p-Wert } \\
\text { A vs B }\end{array}$ & $\begin{array}{l}\text { p-Wert } \\
\text { A vs C }\end{array}$ \\
\hline $\begin{array}{l}\text { Geschlecht }(\mathrm{m} / \mathrm{w}) \mathrm{n} \\
(\%)\end{array}$ & $\begin{array}{l}33 / 19 \\
(63 / 37)\end{array}$ & $\begin{array}{l}29 / 19 \\
(60 / 49)\end{array}$ & $\begin{array}{c}10 / 10 \\
(50 / 50)\end{array}$ & 0,84 & 0,42 \\
\hline $\operatorname{Alter}(\bar{x}, I Q R)$ & $53,2(23-71)$ & $52,6(19-68)$ & $51,2(18-67)$ & 0,84 & 0,61 \\
\hline Ulcerationen & $10(19)$ & $15(31)$ & $13(65)$ & 0,18 & $0,007 * 1$ \\
\hline GvHD n (\%) & $4(8)$ & $8(17)$ & $3(15)$ & 0,22 & 0,39 \\
\hline \multicolumn{6}{|l|}{ Medikation n (\%) } \\
\hline Glucocorticoide & $37(71)$ & $32(67)$ & $14(70)$ & 0,67 & 1,00 \\
\hline Immunsuppressiva & $40(77)$ & $44(92)$ & $20(100)$ & 0,06 & $0,28^{*}$ \\
\hline MMF & $20(39)$ & $21(44)$ & $2(10)$ & 0,68 & $0,28^{*}$ \\
\hline Andere & $6(12)$ & $5(8)$ & $3(15)$ & 1,00 & 0,70 \\
\hline
\end{tabular}

\subsubsection{Analyse nach Anzahl gleichzeitig einzunehmender Immunsuppressiva der CED-Kohorte}

Bei der CED-Kohorte erhielten 56 Patienten mehr als zwei Immunsuppressiva, 42 Patienten davon zählten zu der CMV(-)-Subgruppe und 14 zu der CMV(+)-Subgruppe. Eine statistische Signifikanz war nicht nachweisbar (Tab. 6).

Tab. 6 Anzahl der Immunsuppressiva bei der CED-Kohorte

\begin{tabular}{|lccc|} 
Anzahl & CMV(-) & CMV(+) & p-Wert \\
Immunsuppressiva & $\mathrm{n}=85$ & $\mathrm{n}=20$ & \\
\hline$<2$ & 43 & 6 & 0,14 \\
\hline$\geq 2$ & 42 & 14 & \\
\hline
\end{tabular}

\subsubsection{Analyse nach Anzahl gleichzeitig einzunehmender Immunsuppressiva der STX-Kohorte}

In der STX-Kohorte erhielten 92 Patienten mehr als zwei Immunsuppressiva, wobei innerhalb der Betrachtung des CMV-Status keine Signifikanz deutlich wurde, da bei den CMV(-)-Patienten 38 mehr als zwei und bei den $\mathrm{CMV}(+)$-Patienten 54 mehr als zwei immunsuppressive Medikamente erhielten (Tab. 7). 
Tab. 7 Anzahl der Immunsuppressiva bei der STX-Kohorte

\begin{tabular}{|c|c|c|c|c|c|}
\hline Anzahl & A & B & C & p-Wert & p-Wert \\
\hline Immunsuppressiva & CMV(-) n=52 & CMV(+) n=48 & $\mathrm{CMV}(+)-\mathrm{GE} \quad \mathrm{n}=20$ & A vs B & A vs $C$ \\
\hline$<2$ & 14 & 10 & 4 & 0,49 & 0,76 \\
\hline$\geq 2$ & 38 & 38 & 16 & & \\
\hline
\end{tabular}

\subsection{Diagnostik des CMV-Status}

Im folgenden Abschnitt werden die diagnostische Genauigkeit der verwendeten Methoden bezüglich der Nachweisbarkeit einer CMV-Erkrankung der eingeschlossenen Patienten betrachtet und gegenübergestellt.

Hierzu wurden die Sensitivität, Spezifität, der positiv prädiktive Wert (PPV) und der negative prädiktive Wert (NPV) der verwendeten Methoden berechnet.

\subsubsection{Diagnostische Genauigkeit des CMV-Status der CED-Kohorte}

Bei der Kohorte der CED ergaben sich dabei folgende Ergebnisse (Tab. 8):

Bei der Annahme, dass ein CMV-DNA-PCR-Nachweis von >250 Kopien/ml aus der PE eine Infektion mit nachfolgender Manifestation einer CMV-GE erst wahrscheinlich macht (Roblin et al. 2011), ergab dies eine Steigerung der Sensitivität auf 100\%. Die Spezifität der PCR aus einer PE wurde dabei geringer (89\%), da nun ein DNA-Nachweis von $<250 \mathrm{Kopien} / \mathrm{ml}$ als falsch positiv gewertet wurde.

Tab. 8 Testverfahren zur Diagnosesicherung der CMV-Infektion bei der CED-Kohorte

\begin{tabular}{|lcccc|} 
Test CMV & Sensitivität & $\begin{array}{c}\text { Spezifität } \\
(\%)\end{array}$ & $\begin{array}{c}\text { PPV } \\
(\%)\end{array}$ & $\begin{array}{c}\text { NPV } \\
(\%)\end{array}$ \\
\hline PCR CMV-DNA aus Serum $(\mathrm{n}=105)$ & $(\boldsymbol{\%})$ & 100 & 100 & 92 \\
PCR aus PE $(\mathrm{n}=62)$ & 65 & 100 & 100 & 96 \\
Eulenaugenzellen H\&E der PE $(\mathrm{n}=47)$ & 85 & 100 & 0 & 70 \\
Immunhistochemie der PE $(\mathrm{n}=47)$ & 0 & 100 & 100 & 73 \\
CMV-DNA-PCR $>$ 250 Kopien/ml aus PE $(\mathrm{n}=38)$ & 14 & 89 & 64 & 100 \\
\hline
\end{tabular}




\subsubsection{Diagnostische Genauigkeit des CMV-Status der STX-Kohorte}

Bei der Kohorte der STX ergaben sich folgende Ergebnisse:

Äquivalent zur CED-Kohorte stieg unter der Annahme, dass ein CMV-DNA-PCR-Nachweis von $>250$ Kopien $/ \mathrm{ml}$ aus der PE eine Infektion mit CMV mit nachfolgender Manifestation einer CMV-GE erst wahrscheinlich macht, die Sensitivität auf 100\%. Die Spezifität der PCR aus einer PE wurde dabei geringer (90\%), da nun ein DNA-Nachweis von $<250 \mathrm{Kopien} / \mathrm{ml}$ als falsch positiv gewertet wurde (Tab. 9).

Tab. 9 Testverfahren zur Diagnosesicherung der CMV-Infektion bei der STX-Kohorte

\begin{tabular}{|lcccc|} 
Test CMV & Sensitivitä & Spezifität & PPV & NPV \\
& $(\boldsymbol{\%})$ & $(\%)$ & $(\%)$ & $(\%)$ \\
\hline PCR CMV-DNA aus Serum $(\mathrm{n}=120)$ & 95 & 100 & 100 & 95 \\
PCR aus PE $(\mathrm{n}=92)$ & 95 & 100 & 100 & 97 \\
Eulenaugenzellen H\&E der PE $(\mathrm{n}=61)$ & 5 & 97 & 50 & 37 \\
Immunhistochemie der PE $(\mathrm{n}=61)$ & 5 & 100 & 100 & 38 \\
CMV-DNA-PCR $>$ 250 Kopien/ml aus PE $(\mathrm{n}=50)$ & 100 & 90 & 75 & 100 \\
\hline
\end{tabular}

Mit einbezogen werden sollte grundsätzlich auch, um welche Manifestation der CMV es sich rückblickend bei der STX-Kohorte handelte (Abb. 7). Bei zwei Patienten wurde eine CMV-Pneumonie, bei einem Patienten eine CMV-Enzephalitis und bei 20 Patienten eine CMV-Enteritis diagnostiziert. Die Nachweise erfolgten aus PE aus der BAL, Liquorpunktion oder Endoskopie.

Bei der Mehrzahl der Patienten lag eine Virämie ( $\mathrm{n}=65)$ im Blut vor. Überwiegend überschnitt sich der Nachweis einer Virämie mit dem Nachweis einer CMV-Manifestation in anderen Organsystemen. In einigen Fällen fand ein CMV-DNA-Nachweis nur im betreffenden Organsystem statt ohne eine Virämie. In den meisten Fällen konnte ein CMV-DNA-Nachweis jedoch keinem spezifischen Organsystem mehr zugewiesen werden oder ging primär von Bestandteilen des Blutes aus, was rückblickend nicht lückenlos geklärt werden kann. 


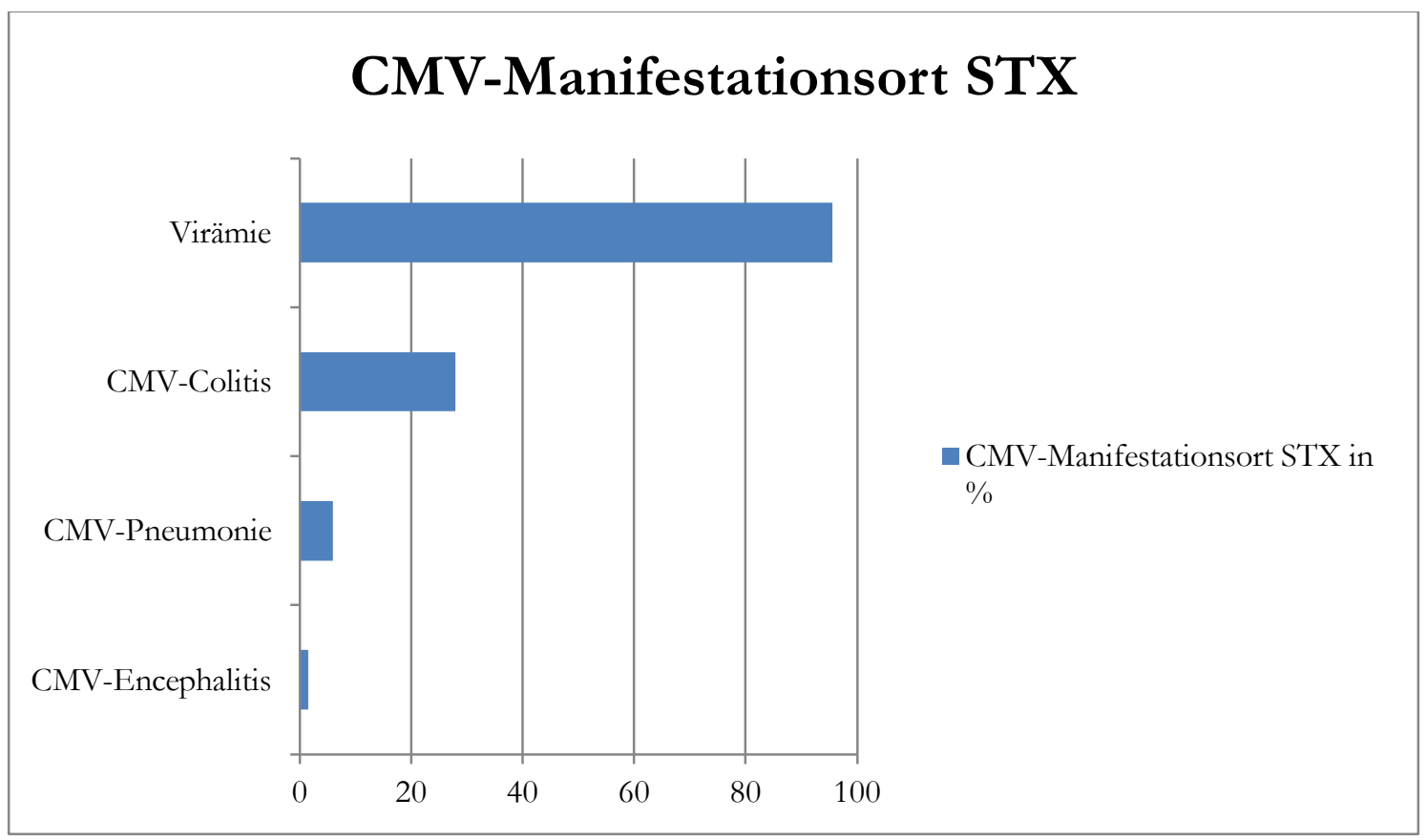

Abb. 7: CMV-Manifestationsort der Kohorte der STX

\subsection{Prädiktive Parameter und Risikofaktoren für eine CMV-Erkrankung}

\subsubsection{Prädiktive Parameter und Risikofaktoren der CED-Kohorte}

In diesem Abschnitt sollen die Ergebnisse dargestellt werden, die sich bei den untersuchten Patientenkollektiven als mögliche prädiktive Parameter oder Risikofaktoren darstellten.

In Abbildung 8 sind die untersuchten Laborparameter der CED-Kohorte gezeigt, die einen diagnostischen Wert haben könnten. In der graphischen Darstellung erscheinen dabei die einzelnen Patientenwerte von den CMV(-)- und den CMV(+)-Patienten im direkten Vergleich zueinander. Der p-Wert ist festgehalten.

Besondere Betrachtung fanden dabei u. a. die in der Literatur oft erwähnte Thrombozytenzahl oder auch das Hämoglobin (Groß 2006). Zusätzlich wurden das Kreatinin, das CRP, die Leukozytenzahl und die ALT auf mögliche Korrelation mit einer CMV-Infektion hin untersucht.

Als prädiktiver Parameter konnte der Hämoglobinwert identifiziert werden. CMV $(+)$-Patienten hatten einen signifikant niedrigeren Hämoglobingehalt des Blutes im Vergleich zu CMV(-)- Patienten ( $\mathrm{p}=0,0001)$ (Abb. 8A).

Die weiteren untersuchten laborchemischen Parameter wie Thrombozyten- und Leukozytenzahl, aber auch der Spiegel von CRP, Kreatinin sowie die ALT-Aktivität, unterschieden sich nicht zwischen den Gruppen (Abb. 8B-F). 

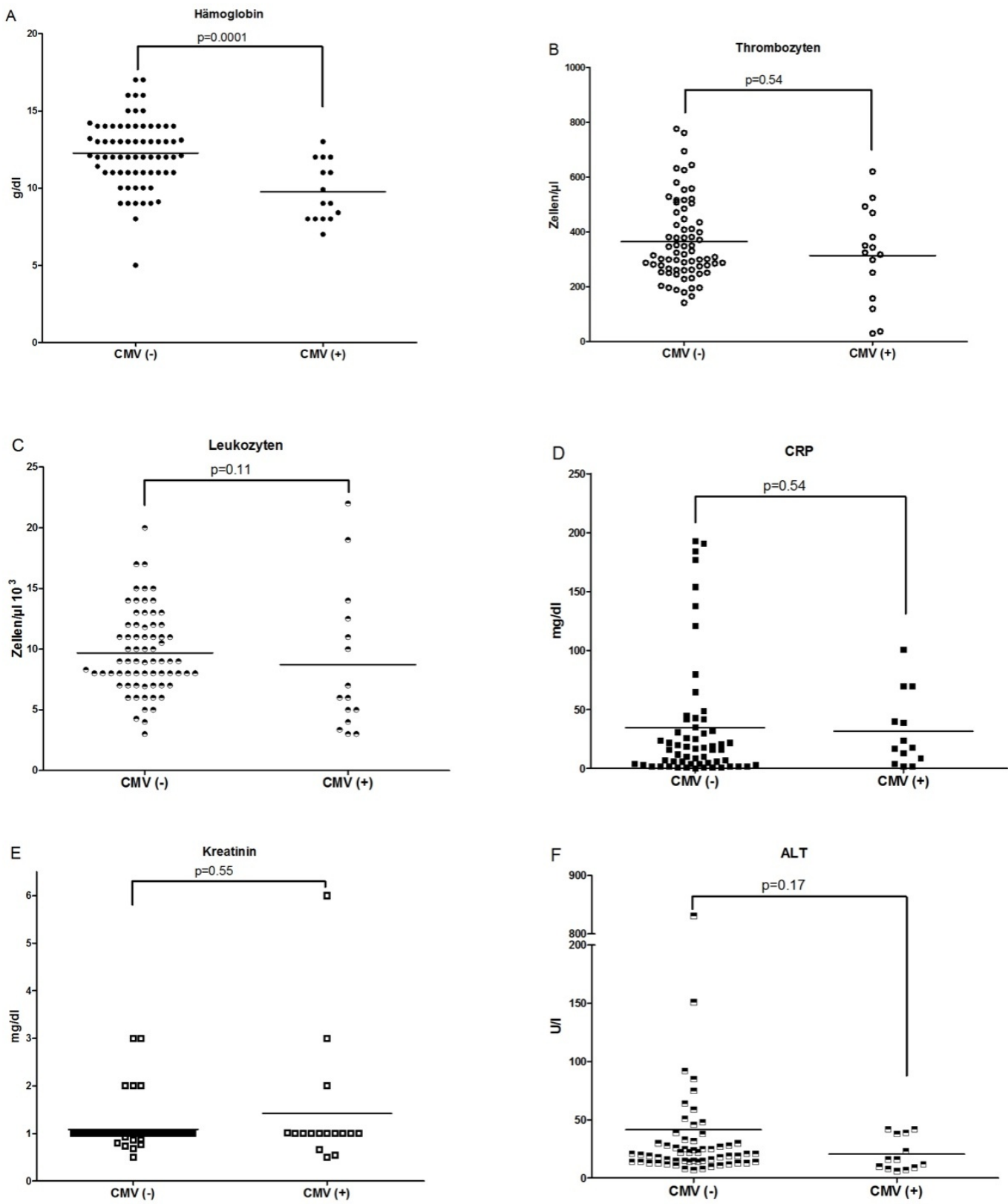

Abb. 8: Laborchemische Parameter der CED-Kohorte dargestellt nach dem CMV-Status

Die ROC-Kurven-Analyse von Hämoglobin lieferte einen area under the curve (AUC) von 0,8162 (Abb. 9A).

Es ergab sich von den vorhandenen Patientendaten eine Odds-Ratio (OR) von 11,6 mit dem dazugehörigen 95\%-Konfidenzinterfall (95\%-CI) (3,3-41,4). CED-Patienten mit Anämie zeigten signifikant häufiger eine CMV-Infektion als CED-Patienten ohne Anämie (Abb. 9B). 
A

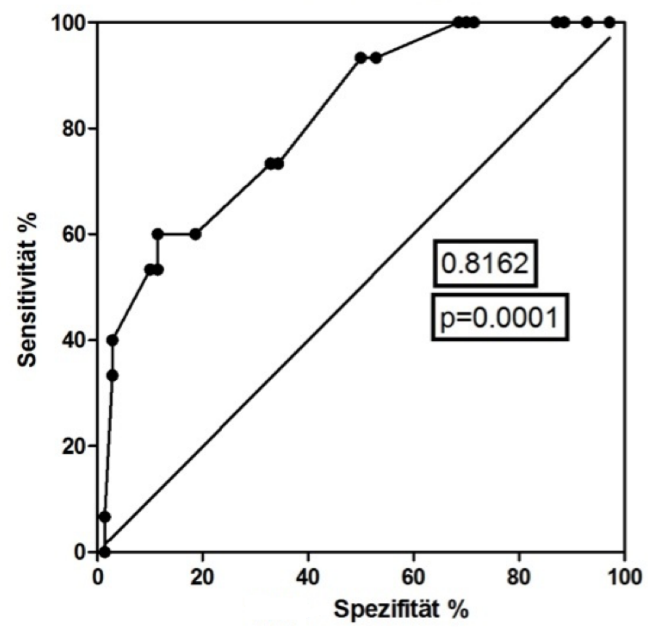

B

Hb CED

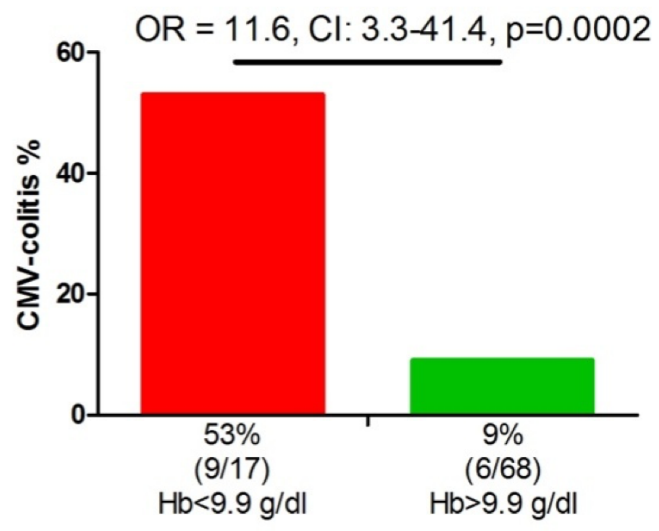

Abb. 9: ROC-Analyse von Hämoglobin, Cut-off sowie Odds ratio von Hämoglobin der CED-Kohorte

Die täglich eingenommene Cortisondosis in $\mathrm{mg}$ war signifikant mit einer CMV-Erkrankung assoziiert ( $\mathrm{p}=0,02$ bzw. 0,0435 nach der Bonferroni-Korrektur). Die durchschnittlich tägliche Cortisondosis war bei CMV(+)-Patienten erhöht im Vergleich zu CMV(-)-Patienten.

Mittels der ROC-Kurven-Berechnung konnte eine tägliche Cortisondosis von $10 \mathrm{mg}$ als Risikofaktor für eine Manifestation einer CMV-Infektion ermittelt werden (Abb. 10A). Die AUC der täglich einzunehmenden Cortisondosis beträgt 0,6958.

Die OR sowie das entsprechende 95\%-CI als Risikoverhältnis wurden in der Abb. 10B festgehalten. CED-Patienten mit einer täglichen Cortisondosis von $>10 \mathrm{mg} / \mathrm{d}$ hatten im Vergleich zu CED-Patienten mit einer Cortisondosis $<10 \mathrm{mg} / \mathrm{d}$ einen 4,4fach erhöhtes Risiko an einer CMV-Infektion zu erkranken. 
A

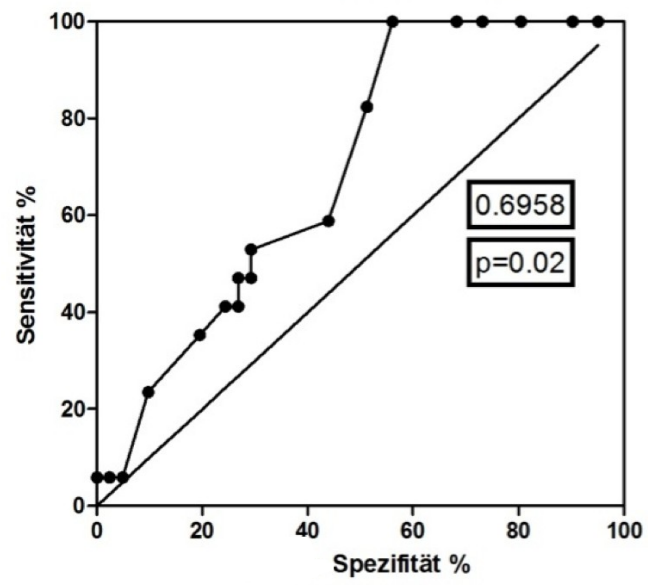

B

Cortison CED

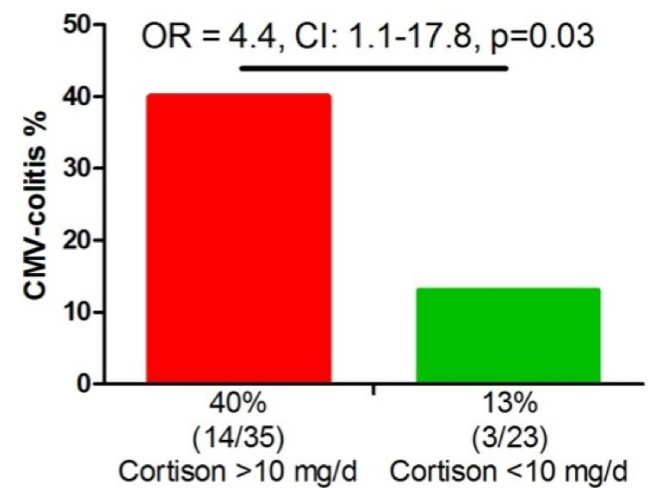

Abb. 10: ROC der täglichen Einnahme von Cortisondosis, Cut-off und Odds ratio von Cortison der CED-Kohorte

\subsubsection{Prädiktive Parameter und Risikofaktoren der STX-Kohorte}

In der STX-Kohorte wurden der Hämoglobinwert, die Thrombozyten- und Leukozytenzahl, das CRP, das Kreatinin sowie die ALT mit der Fragestellung untersucht, ob diese eine diagnostische Bedeutung spielen könnten bezüglich einer CMV-Infektion. Das Albumin und das Gesamtprotein sind zusätzlich graphisch dargestellt. Anders als in der CED-Kohorte erfolgte eine Unterteilung in drei Subgruppen: CMV(-)-, CMV(+)- und CMV(+)-GE-Patienten.

Die Laborparameter zeigten im Vergleich keine Korrelation bezüglich einer CMV-Gastroenteritis (Abb. 11A-H). Die statistische Analyse der täglich eingenommenen CyA-, Tacrolimus- und Everolimusdosis in mg ergibt keine Unterschiede zwischen den einzelnen Subgruppen (Daten nicht gezeigt). 

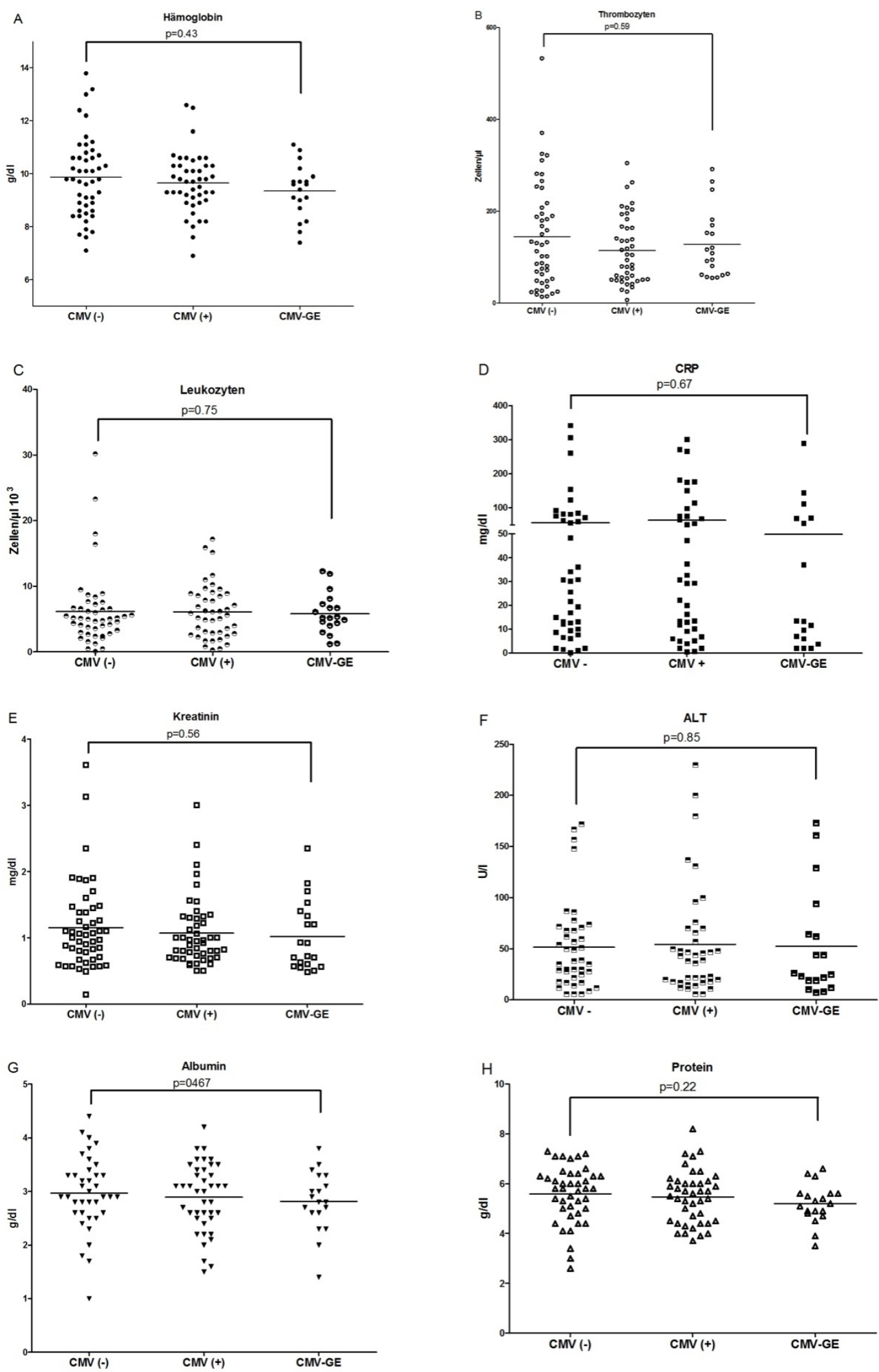

Abb. 11: Laborchemische Parameter der STX-Kohorte dargestellt nach dem CMV-Status 


\subsection{Antivirale Therapie der CMV-Erkrankung und Ansprechrate der behandelten Patienten}

\subsubsection{Antivirale Therapie und Ansprechrate der CED-Kohorte}

In der CED-Kohorte erfolgte eine antivirale Therapie bei 70\% (14/20) der Patienten mit einer CMV-Gastroenteritis $(\mathrm{CMV}(+))$.

Die Letalität der CMV(+)-Gruppe betrug 10\% (2/20) und es verstarb kein Patient der CMV(-)-Gruppe $(p=0,03)$. Todesursache dieser zwei Patienten war eine Sepsis. Die Gesamtmortalität betrug in der CED-Kohorte $2 \%$.

\subsubsection{Antivirale Therapie und Ansprechrate der STX-Kohorte}

Eine antivirale Therapie erhielten 75\% der STX-Patienten (36/48) mit einem CMV (+)-Nachweis. Ebenso wurde bei 75\% der CMV(+)-GE-Patienten (15/20) eine antivirale Therapie durchgeführt. Die Letalitätsrate war in dieser Studie nicht signifikant $(p=0,35)$. Ursachen für das Versterben waren vielfältig. So starben bei den CMV(-)-Patienten sieben an einer Sepsis, zwei an Pneumonie und einer am Progress des malignen Grundleidens. Bei den CMV(+)-Patienten starben drei an einer GvHD, drei an einer Sepsis, zwei an CMV-Pneumonie und sieben Patienten aufgrund anderer Ursachen.

In der $\mathrm{CMV}(+)-G E-G r u p p e$ starben zwei Patienten aufgrund einer Sepsis und MultiOrganversagen, einer aufgrund einer pulmonalen Dekompensation und einer an einer GvHD. Bei zwei Patienten wurde die CMV als Todesursache angenommen. Ein Patient starb an einer CMV-Colitis mit gleichzeitiger CMV-Pneumonie und einer aufgrund einer Perforation während der Koloskopie bei CMV-Colitis. Aufgrund der Vielfältigkeit der Gründe des Versterbens sind die Daten nicht graphisch aufgeschlüsselt. Insgesamt verstarben 31 Patienten der STX-Kohorte im Betrachtungszeitraum. 
A Letalität der CED-Kohorte

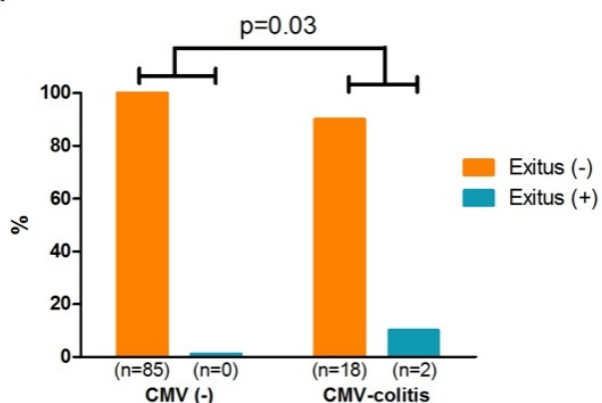

B Letalität der STX-Kohorte

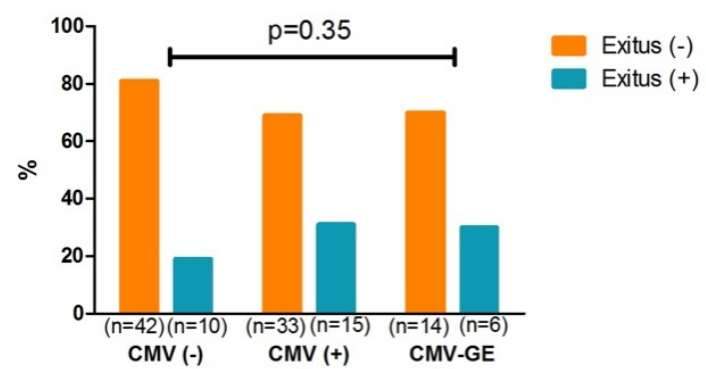

Abb. 12: Letalität der CED- und STX-Kohorte in Abhängigkeit vom CMV-Status 


\section{Diskussion}

Die Hauptergebnisse dieser Studie bezogen auf die Fragestellung aus den eingeschlossenen CED- und STX-Kohorten sind: (1.) die diagnostische Genauigkeit für die quantitative CMV-DNA-PCR als "Goldstandard"-Methode zur Diagnostik einer gastrointestinalen CMV-Erkrankung ist hochsensitiv und spezifisch, (2.) die Verwendung von Glucocorticoiden oder immunsuppressiven Medikamenten sind Risikofaktoren für eine CMV-Colitis in der CED-Kohorte, (3.) als prädiktive Faktor zeigte sich in der CED-Kohorte ein erniedrigter Hämoglobinspiegel sowie (4.) als prädiktive Faktor der STX-Kohorte konnte der Nachweis von endoskopischen Ulcera identifiziert werden. Eine Zunahme der Mortalitätsrate (5.) durch eine zusätzliche CMV-Erkrankung konnte in der Kohorte der STX nicht gezeigt werden. Allerdings ergab sich eine Signifikanz bezüglich der Mortalität zwischen den CMV(-)- und den CMV(+)-Patienten der CED-Kohorte. Ein Einfluss durch Polypharmazie (6.) auf eine CMV-Erkrankung oder eine CMV-Reaktivierung konnte nicht evaluiert werden.

\subsection{Prädiktive Parameter, Risikofaktoren und diagnostische Genauigkeit der verwendeten Methoden}

Die Empfindlichkeit der H\&E-Färbung und IHC für die CED- und die STX-Kohorte waren in dieser Studie extrem niedrig. Frühere Studien, welche auch die diagnostische Genauigkeit der H\&E-Färbung untersuchten, konnten ebenfalls maximal eine Sensitivität von 10\% zeigen (Kandiel und Lashner 2006). Das Hauptproblem dieser Technik zur Diagnostik einer gastrointestinalen CMV-Erkrankung besteht darin, dass die Durchführung durch einen entsprechend ausgebildeten Pathologen vorgenommen werden muss. Daher wird als zusätzliches Verfahren zur weiteren Verbesserung des diagnostischen Werts von histologischen Techniken IHC empfohlen. Unter Verwendung von monoklonalen Antikörpern gegen CMV-Immediate-Early-Antigene in infizierten Zellen kann die Sensitivität dieser Methode auf maximal 78\% erhöht werden (Kandiel und Lashner 2006; Rahbar et al. 2003).

Um eine ausreichende Empfindlichkeit zu erreichen, müsste jedoch eine große Anzahl von Biopsieproben untersucht werden (McCurdy et al. 2015; Claussen 2009), welche sich in der täglichen Praxis als schwierig gestaltet bzw. nur wenige endoskopisch tätige Ärzte hiervon Kenntnis haben. So ist die Wahrscheinlichkeit des Antreffens von Eulenaugenzellen bei einer Probeentnahme sehr gering. So könnten sich theoretisch an anderen Stellen der ulcerativen Läsionen mehrere pathologische Zellen befinden, die so aber nicht erfasst und erkannt werden. 
Aufgrund der geringen diagnostischen Signifikanz dieser zwei Techniken sollten alternative diagnostische Verfahren als ein Goldstandard in der Zukunft evaluiert und festgelegt werden. Die in dieser Studie gefundenen Ergebnisse zeigen die Eignung der quantitativen PCR-Analyse zu diesem Zweck.

Bis heute haben nur wenige veröffentlichte Studien die diagnostische Genauigkeit quantitativer CMV-DNA-PCR-Amplifikationstests in der Darmschleimhaut untersucht. Insgesamt konnten sie aber die größte Genauigkeit für den CMV-Nachweis zeigen (Rahbar et al. 2003; Roblin et al. 2011; Domènech et al. 2008; Yoshino et al. 2007; Kou et al. 2006; Yoshino et al. 2012; Yamada et al. 2014; Ciccocioppo et al. 2015; Minami et al. 2015; Okahara et al. 2017).

Ein Nachteil der PCR-Diagnostik ist die Tatsache, dass nur ein Genom nachgewiesen wird. Ob es sich hierbei tatsächlich um z.B. eine manifeste Infektion handelt, kann häufig daraus nicht entschieden werden. Dies legt die Vermutung nahe, dass der Nachweis von niedrigen Kopien von CMV-DNA eine latente Infektion aufweisen kann. Daher kann ein Cut-Off-Wert der Virämie eine latente CMV-Infektion von einer manifesten CMV-Erkrankung unterscheiden (Lawlor und Moss 2010; Roblin et al. 2011). Robin et al. konnten einen Cut-off-Wert von >250 Kopien/ml der CMV-DNA für eine CMV-Erkrankung mit einer Sensitivität von 100\% und einer Spezifität von 66\% ermitteln. In Analogie zu den Ergebnissen dieser genannten Studie hat die aktuelle Studie eine Sensitivität und Spezifität von 100\% und 89\% für den Cut-Off-Wert von >250 Kopien/ml CMV-DNA für die CED-Kohorte ermittelt. Einer der wichtigsten Nachteile dieser Methoden liegt in einer mangelnden Standardisierung, sodass ein Vergleich der Ergebnisse zwischen verschiedenen Studien schwierig ist. Daher sollte zukünftig ein allgemein akzeptierter Cut-Off-Wert der CMV-DNA-Last zur Beurteilung einer CMV-Erkrankung definiert werden.

Bisher existiert keine Studie, die einen Cut-Off-Wert von >250 CMV-DNA Kopien/ml aus PE des Magen-Darm-Traktes bei STX-Patienten untersuchte. In der vorliegenden Studie beträgt die Empfindlichkeit von H\&E- und IHC-Methoden für den Nachweis einer CMV-Gastroenteritis in der STX-Kohorte jeweils nur 5\%. Diese Annahme würde bedeuten, dass viele STX-Patienten als falsch-negativ diagnostiziert würden, wenn diese Verfahren allein zur Diagnostik herangezogen werden würden. Dies hätte zur Folge, dass viele Patienten eine falsche Therapie erhalten hätten (Bhutani et al. 2015; Dahi et al. 2015; Wu et al. 2017).

\subsubsection{Prädiktive Parameter, Risikofaktoren und diagnostische Genauigkeit der verwendeten Methoden der CED-Kohorte}

Als prädiktiver Faktor zeigte ein erniedrigter Hämoglobinspiegel in der CED-Kohorte auf eine CMV-Colitis hin. Darüber hinaus konnte die vorliegende Studie zwei Risikofaktoren für das Auftreten einer CMV-Colitis in der CED-Kohorte darlegen, u. a. die Einnahme von höheren 
Dosen von Corticosteroiden und die Behandlung mit immunsuppressiven Wirkstoffen wie Calcineurininhibitoren. CED-Patienten unter höheren Dosen von Corticosteroidtherapie hatten ein 6,1 fach erhöhtes Risiko an einer CMV-Colitis zu erkranken als CED-Patienten unter niedriger bzw. keiner Corticosteroidtherapie. Es konnte ermittelt werden, dass die Corticosteroiddosis ( $>10 \mathrm{mg}$ pro Tag) für die Manifestation einer CMV-Colitis bei CED-Patienten relevant ist. Die Medikation mit Cortikosteroiden in der CED-Kohorte ist ein bereits bekannter Risikofaktor für CMV-Erkrankungen (Yoshino et al. 2007, Ciccocioppo et al. 2015; Cottone er al. 2001; Maconi et al. 2005). Noch ausgeprägter schien das Risiko an einer CMV-Colitis zu erkranken für immunsuppressive Wirkstoffe wie Cyclosporin A oder Tacrolimus bei CED-Patienten zu sein. Patienten mit den genannten Immunsuppressiva hatten ein 16,6fach erhöhtes Risiko an einer CMV-Colitis zu erkranken als CED-Patienten ohne Immunsuppressiva. Entsprechend dem Ergebnis der vorliegenden Studie hat nur eine weitere Studie die Tagesdosis von Corticosteroiden als Risikofaktor untersucht. Resultat dieser Studie war, dass CED-Patienten mit Cortikosteroiden von mehr als $10 \mathrm{mg}$ pro Tag ein erhöhtes Risiko für CMV-Colitis hatten (Cottone et al. 2001).

In Bezug auf die immunsuppressive Therapie wurden Cyclosporin A und Tacrolimus als Risikofaktoren für die Entwicklung einer CMV-Colitis in der CED-Kohorte assoziiert. Dies steht im Einklang mit bereits veröffentlichten Studien, in denen die Verwendung von Calcineurin-Inhibitoren als Risikofaktoren für die CMV-Beteiligung des Darms auftraten (Minami et al. 2007; Domènech et al. 2008; Jones et al. 2015).

Bei CED-Patienten ergaben sich widersprüchliche Studienergebnisse zwischen dem Nachweis von Ulcerationen während der Endoskopie und einer CMV-Krankheit. Während einige Studien einen Zusammenhang zwischen endoskopisch nachweisbaren Ulcerationen und CMV-Erkrankungen zeigen konnten (McCurdy et al. 2015; Hirayama et al. 2016), konnte eine weitere Studie dieses Resultat nicht bestätigen (Roblin et al. 2011).

Bezüglich der Diagnostik einer CMV-Erkrankung ergab sich die höchste Sensitivität beim CMV-DNA-Nachweis aus PE. Bei der Annahme, dass ein CMV-DNA-PCR-Nachweis von $>250 \mathrm{Kopien} / \mathrm{ml}$ aus der PE eine Infektion mit nachfolgender Manifestation einer CMV-GE erst wahrscheinlich macht (Roblin et al. 2011), ergab dies eine zusätzliche Steigerung der Sensitivität. Die Spezifität der PCR aus einer PE wurde dabei aber geringer (89\%), da nun ein DNA-Nachweis von $<250 \mathrm{Kopien/ml} \mathrm{als} \mathrm{falsch} \mathrm{positiv} \mathrm{gewertet} \mathrm{werden} \mathrm{müsste.}$

\subsubsection{Prädiktive Parameter, Risikofaktoren und diagnostische Genauigkeit der verwendeten Methoden der STX-Kohorte}

In der Kohorte der STX-Patienten konnte nur der endoskopische Nachweis von gastrointestinalen Ulcerationen als ein unabhängiger Prädiktor für die Manifestation einer 
CMV-Gastroenteritis mit einem OR von 7,8 eruiert werden. Somit kann der Nachweis von Ulcerationen bei einem immunsuppremierten STX diagnostisch als richtungsweisend für eine gastrointestinale CMV-Manifestation angesehen werden. Diese Studie ist die erste ihrer Art, welche die endoskopischen Befunde in einer größeren STX-Kohorte evaluiert und dieses Ergebnis zeigen kann.

Nur eine zuvor veröffentlichte Studie an STX-Patienten berichtete über den Zusammenhang zwischen CMV-Gastritis und Ösophagogastroduodenoskopie. In dieser Studie wurde jedoch keine Koloskopie durchgeführt und damit die Beteiligung des unteren Gastrointestinaltrakts nicht näher beleuchtet (Kakugawa et al. 2010).

Signifikante Risikofaktoren konnten innerhalb der STX-Kohorte nicht eruiert werden. Es ergaben sich weder laborchemisch noch durch eingesetzte immunsuppressive Medikamente Hinweise auf eine drohende CMV-Infektion.

In den statistischen Analysen bezüglich der Diagnostik ergab sich in der STX-Kohorte die höchste Sensitivität bezüglich der unterschiedlichen Testverfahren im Nachweis von CMV-DNA aus dem Serum und der PE. Äquivalent zur CED-Kohorte stieg die Sensitivität bei der Annahme, dass ein CMV-DNA-PCR-Nachweis von >250 Kopien/ml aus der PE eine Infektion mit nachfolgender Manifestation einer CMV-GE erst wahrscheinlich macht.

\subsection{Antivirale Therapie und therapeutisches Ansprechen}

\subsubsection{Antivirale Therapie und therapeutisches Ansprechen der CED-Kohorte}

Die ECCO (Rahier et al. 2009) und das American College of Gastroenterology (Kornbluth und Sachar 2004) haben bezüglich einer CMV-Colitis/Gastroenteritis Leitlinien entwickelt. Diese empfehlen die Behandlung der CMV-Krankheit, wenn der Nachweis der Infektion in Magen-Darm-Gewebe bestätigt wird. 70\% der Patienten mit CMV-Colitis der CED-Kohorte wurden antiviral behandelt.

Bei einigen Patienten war eine Dosisreduktion der immunsuppressiven Medikamente ausreichend, insbesondere in der CED-Kohorte (Daten nicht gezeigt). In Bezug auf CED ist es aus Mangel an evidenzbasierter Medizin schwierig, auf die Rolle der antiviralen CMV-Therapie zurückzuschließen. Verschiedene gastroenterologische Fachgesellschaften (Rahier et al. 2009; Kornbluth und Sachar 2004) empfehlen eine antivirale Behandlung, wenn es zu einem schweren Verlauf der Krankheitsaktivität der CED kommt, bei gleichzeitigem Nachweis einer CMV im entzündeten Gewebe. Empfehlungen zu antiviralen Medikamenten oder der Behandlungsdauer gibt es allerdings nicht. Basierend auf den Ergebnissen meist retrospektiver Studien wird eine antivirale Therapie mit Ganciclovir intravenös begonnen. Nach etwa 14-tägiger Behandlung 
erfolgt eine Umstellung der Therapie auf orales Valganciclovir für insgesamt ca. drei Monate (Shukla et al. 2015; Pillet et al. 2016).

Die Signifikanz und die Rate von CMV-Rezidiven während oder nach der antiviralen Behandlung sind unbekannt.

Die Mortalitätsrate der CED-Kohorte betrug in der vorliegenden Studie 2\% (2/105) der eingeschlossenen Patienten aufgrund einer Sepsis. Beide CED-Patienten waren an einer CMV-Colitis erkrankt.

\subsubsection{Antivirale Therapie und therapeutisches Ansprechen der STX-Kohorte}

75\% der Patienten mit CMV-Gastroenteritis der STX-Kohorte erhielten eine antivirale Therapie nach der Entscheidungsfindung ihres Arztes.

Vor allem in der STX-Kohorte führte die zugrundeliegende Krankheit häufig zum Tode, weshalb eine Therapie der CMV in einigen Fällen nicht mehr erfolgte.

Im Gegensatz zu Patienten mit einer CED sollte eine CMV-Erkrankung bei Patienten nach einer STX immer antiviral therapiert werden, um die Morbidität und Mortalität zu reduzieren (Bowden et al. 1986; Goodrich et al. 1991), da eine zusätzliche CMV-Krankheitsmanifestation laut Literatur die Mortalitätsrate auf 80\% steigert (Roberts et al. 2010).

Die Mortalitätsrate der STX-Kohorte der vorliegenden Studie war 26\% (31/120). Interessanterweise war die Letalitätsrate der STX-Kohorte in dieser Studie nicht mit dem CMV-Status assoziiert. Dies legt die Vermutung nahe, dass eine zusätzliche CMV-Infektion die Morbidität steigert, aber die Mortalität nicht beeinflusst.

\subsection{Limitationen der Studie}

$\mathrm{Zu}$ den Einschränkungen dieser Studie gehören der retrospektive Charakter und das monozentrische Studiendesign. Die Anzahl der eingeschlossenen Patienten war relativ gering, aber dennoch größer als in den meisten bereits veröffentlichten Studien zur quantitativen Bestimmung der CMV-DNA (Roblin et al. 2011; Yoshino et al. 2007).

Warum nicht alle eingeschlossenen Patienten beider Kohorten antiviral behandelt wurden, bleibt aufgrund der retrospektiven Datenauswertung spekulativ. Gründe hierfür könnten sein, dass einige Patienten beider Kohorten eine niedrige Virämie durch quantitative 
CMV-DNA-PCR-Analyse zeigten und dadurch eine wahrscheinlich geringe Krankheitsaktivität trotz Diagnose der CMV-Erkrankung aufwiesen.

Die Behandlungsstrategie basierte auf den Entscheidungen jedes Arztes und den Präferenzen der Patienten. Die vorliegenden Ergebnisse umfassen zwei heterogene Kohorten, die sich möglicherweise von früheren CED- und STX-Studien unterschieden, die den klinischen Verlauf der CMV-Erkrankung untersuchten (Roblin et al. 2011; Yoshino et al. 2007; Roberts et al. 2010, Bhutani et al. 2015). 


\section{$5 \quad$ Zusammenfassung}

Bei dieser Untersuchung handelt es sich um eine retrospektive, monozentrische Studie, in der die erfassten Daten von Patienten mit einer CED oder einer STX analysiert wurden, welche sich zwischen Januar 2005 und Dezember 2016 in der Universitätsmedizin Göttingen mindestens einmal aufgrund ihrer Grunderkrankung in Behandlung befanden. Diese Zusammenschau untersuchte Patientendaten hinsichtlich einer CMV-Infektion bzw. -Manifestation. 105 CED- und 120 STX-Patienten mit bekanntem CMV-Serostatus bildeten die untersuchten Kohorten.

Eine Unterscheidung erfolgte in beiden Kohorten von CED und STX zwischen einem CMV(-)- und einem CMV(+)-Status. Eine Evaluation folgte, wie die Diagnose der CMV-Erkrankung zustande kam (PCR aus EDTA, H\&E, IHC oder PCR aus Probeentnahmen). Des Weiteren fand eine Zusammentragung der Daten bezüglich der Medikation, verschiedener Laborparameter und endoskopischer Befunde zum Zeitpunkt der jeweiligen Diagnostik statt. Anschließend erfolgte eine statistische Analyse.

Ein Anhalt für das Vorliegen einer tatsächlichen CMV-Infektion wurde durch den Nachweis der DNA aus dem Blut angenommen, aber auch kritisch hinterfragt, da bei einigen Patienten der Nachweis von CMV-DNA zuerst aus der PE gelang, noch bevor sich eine Virämie im Blut manifestierte. Ein Nachweis von CMV durch eine histologische oder immunhistochemische Betrachtung gelang selten. Deutlich häufiger konnte eine CMV-Erkrankung durch die PCR-Untersuchung nachgewiesen werden.

Diese Studie zeigt, dass die Form der Diagnostik und auch die Therapieentscheidung beim behandelnden Arzt liegt, da bisher keine einheitlichen Maßstäbe existieren, weder für die Diagnostik der CMV-Gastroenteritis bzw. Manifestationsformen der CMV im Allgemeinen, noch bezüglich des Zeitpunkts, ab dem eine definitive Therapie erfolgen sollte, zumindest bei CED-Patienten.

Bezüglich der Mortalität im Zusammenhang mit einer CMV-Erkrankung kamen nur Patienten in Betracht, die sich zu diesem Zeitpunkt in unmittelbarer stationärer Behandlung befanden. Eine gesteigerte Sterblichkeit bezüglich dieser Co-Infektion konnte bei der CED-Kohorte gezeigt werden $(\mathrm{p}=0,03)$, jedoch nicht bei der STX-Kohorte.

Die neue "Goldstandard"-Methode für den Nachweis einer CMV-Gastroenteritis kann eine quantitative CMV-DNA-PCR aus entzündetem Magen-Darm-Gewebe mit einem Cut-off-Wert von $>250$ Kopien sein. Dies sollte jedoch in prospektiven Studien weiter evaluiert werden.

In der CED-Kohorte war ein verminderter Hämoglobinspiegel ein prädisponierender Faktor, während die Einnahme von Corticosteroiden oder Immunsuppressiva sich als Risikofaktoren bezüglich einer CMV-Colitis herausstellten. Darüber hinaus scheint der Nachweis von Ulcerationen während der Endoskopie ein prädiktiver Faktor für eine CMV-Gastroenteritis bei 
STX-Patienten zu sein. Bei Vorliegen dieser Faktoren ist eine CMV-Erkrankung anzunehmen und sollte daher eine zielgerichtete Diagnostik und Therapie eingeleitet werden. In beiden Kohorten ist eine sorgfältige Überwachung der Patienten hinsichtlich einer CMV-Erkrankung erforderlich. 


\section{$6 \quad$ Literaturverzeichnis}

Bhutani D, Dyson G, Manasa R, Deol A, Ratanatharathom V, Ayash L, Abidi M, Lum L, AlKadhimi Z, Uberti J (2015): Incidence, Risk Factors, and Outcome of Cytomegalovirus Viremia and Gastroenteritis in Patients with Gastrointestinal Graft-versus-Host Disease. Biol Blood Marrow Transplant 21, 159-164

Bowden R, Sayers M, Floumoy N, Newton B, Banaji M, Thomas E, Meyers J (1986):

Cytomegalovirus immune globulin and seronegative blood products to prevent primary cytomegalovirus infection after marrow transplantation. N Engl J Med 314, 1006-1010

Britt W, Boppana S (2014): Human cytomegalovirus virion proteins. Hum Immunol $\underline{65}$, 395402

Ciccocioppo R, Racca F, Paolucci S, Campanini G, Pozzi L, Betti E, Riboni R, Vanoli A, Baldanti F, Corazza G (2015): Human cytomegalovirus and Epstein-Barr virus infection in inflammatory bowel disease: need for mucosal viral load measurement. World J Gastroenterol 21, 1915-1926

Claussen M: CMV-Infektion mit gastrointestinaler Manifestation: Vergleich der diagnostischen Möglichkeiten von endoskopischer, pathologischer und virologischer Untersuchung. Med. Diss. Leipzig 2009

Cottone M, Pietrosi G, Martorana G (2001): Prevalence of cytomegalovirus infection in severe refractory ulcerative and Crohn's colitis. Am J Gastroenterol $\underline{96}, 773-775$

Cvetkovic R, Wellington K (2005): Valganciclovir: a review of ist use in the mangement of CMV infection and disease in immunocompromised patients. Drugs $\underline{65}, 859-878$

Dahi P, Perales M, Devlin S, Olason A, Lubin M, Gonzales A, Scaradavou A, Keman N, O’Reilly R, Giralt S, et al. (2015): Incidence, nature and mortality of cytomegalovirus infection after double-unit cord blood transplant. Leuk Lymphoma 56, 1799-1805

de Jong M, Galasso G, Gazzard B, Griffiths P, Jabs D, Kem E, Spector S (1998): Summary of the II International Symposium on Cytomegalovirus. Antiviral Res 39, 141-162

DeLong E, DeLong D, Clark-Pearson D (1988): Comparing the areas under two or more correlated receiver operating characteristic curves: a nonparametric approach. Biometrics $\underline{44}, 837-845$

Domènech E, Vega R, Ojanguren I, Hernández A, Garcia-Planella E, Bernal I, Rosinach M, Boix J, Cabré E, Gassull M (2008): Cytomegalovirus infection in ulcerative colitis: a prospective, comparative study on prevalence and diagnostic strategy. Inflamm Bowel Dis $\underline{14}, 1373-1379$

Fegeler W, Herbst H: Infektionskrankheiten durch Viren; In: Böcker W, Denk H, Heitz U (Hrsg.): Pathologie. 3. Auflage; Urban und Fischer/Elsevier, München 2004, 1130-1139

Goodgame R (1993): Gastrointestinal cytomegalovirus disease. Ann Intern Med 119, 924 935 
Goodrich J, Mori M, Gleaves C, Du Mond C, Cays M, Ebeling D, Buhles W, DeArmond B, Meyers J (1991): Early Treatment with Ganciclovir to Prevent Cytomegalovirus Disease after Allogenic Bone Marrow Transplantation. N Engl J Med 325, 1601-1607

Groß U: Kurzlehrbuch Medizinische Mikrobiologie und Infektiologie. 1. Auflage; Georg Thieme, Stuttgart 2006

Hirayama Y, Ando T, Hirooka Y, Watanabe O, Miyahara R, Nakamura M, Yamamura T, Goto H (2016): Characteristic endoscopic findings and risk factors for cytomegalovirusassociated colitis in patients with active ulcerative colitis. World J Gastrointest Endosc $\underline{8}, 301-309$

Hirsch H: Transplantationsvirologie; In: Doerr HW, Gerlich WH (hrsg.): Medizinische Virologie: Grundlagen, Diagnostik, Prävention und Therapie viraler Erkrankungen. 2. Auflage; Thieme, Stuttgart 2010, 288-298

Jones A, McCurdy J, Loftus E, Bruining D, Enders F, Killian J, Smyrk T (2015): Effects of antiviral therapy for patients with inflammatory bowel disease and a positive intestinal biopsy for cytomegalovirus. Clin Gastroenterol Hepatol 13, 949-955

Kakugawa Y, Kami M, Matsuda T, Saito Y, Kim S, Fukuda T, Mori S, Shimoda T, Tanosaki R, Saito D (2010): Endoscopic diagnosis of cytomegalovirus gastritis after allogeneic hematopoietic stem cell transplantation. World J Gastroenterol 16, 2907-2912

Kambham N, Vij R, Cartwright C, Longacre T (2004): Cytomegalovirus infection in steroidrefractory ulcerative colitis: a case-control study. Am J Surg Pathol 28, 365-373

Kandiel A, Lashner B (2006): Cytomegalovirus Colitis Complicating Inflammatory Bowel Disease. Am J Gastroenterol 101, 2857-2865

Kim C, Bahng S, Kang K, Ku B, Jo J, Kim J, Chang D, Son H, Rhee P, Kim J (2010): Cytomegalovirus colitis in patients without inflammatory bowel disease: a singlecenter study. Scand J Gastroenterol $\underline{45}, 1295-1301$

Kishore J, Ghoshal U, Ghoshal U, Krishnani N, Kumar S, Singh M, Ayyagari A (2004): Infection with cytomegalovirus in patients with inflammatory bowel disease: prevalence, clinical significance and outcome. J Med Microbiol 53, 1155-1160

Kojima T, Watanabe T, Hata K, Shinozaki M, Yokoyama T, Nagawa H (2006): Cytomegalovirus infection in ulcerative colitis. Scand J Gastroenterol 41, 706-711

Kornbluth A, Sachar D (2004): Ulcerative ColitisPractice Guidelines in Adults (Update): American College of Gastroenterology, Practice Parameters Committee. Am J Gastroenterol 9ㅜ, 1371-1385

Korndewal M, Mollema L, Tcherniaeva I, van der Klis F, Kroes A, Oudesluys-Murphy A, Vossen A, de Melker H (2015): Cytomegalovirus infection in the Netherlands: seroprevalence, risk factors, and implications. J Clin Virol $\underline{63}, 53-58$

Kou T, Nakase H, Tamaki H, Kudo T, Nishio A, Chiba T (2006): Cytomegalovirus Infection in Patients with Ulcerative Colitis Diagnosed by Quantitative Real-Time PCR Analysis. Dig Dis Sci $\underline{51}, 1052-1055$ 
Kucharzik T, Dignass A, Atreya, Bokemeyer B, Esters P, Herrlinger K, Kannengießer K, Kienle P, Langhorst J, Lüngering A, et al. (2018): Aktualisierte S3-Leitlinie Colitis ulcerosa der Deutschen Gesellschaft für Gastroenterologie, Verdauungs- und Stoffwechselkrankheiten (DGVS). Z Gastroenterol 56, 1087-1169

Lawlor G, Moss A (2010): Cytomegalovirus in inflammatory bowel disease: pathogen or innocent bystander? Inflamm Bowel Dis $\underline{16}, 1620-1627$

Maconi G, Colombo E, Zerbi P, Sampietro G, Fociani P, Bosani M, Cassinotti A, Casini V, Russo A, Ardizzone S, et al. (2005): Prevalence, detection rate and outcome of cytomegalovirus infection in ulcerative colitis patients requiring colonic resection. Dig Liver Dis $\underline{37}, 418-423$

McCurdy J, Jones A, Killian J, Loftus E, Smyrk T, Bruining D (2015): A Model for Identifying Cytomegalovirus in Patients With Inflammatory Bowel Disease. Clin Gastroenterol Hepatol 13, 131-137

McGavin J, Goa K (2001): Ganciclovir: an update of its use in the prevention of cytomegalievirus infection and disease in transplant recipients. Drugs 61, 1153-1183

Minami M, Ohta M, Okhura T, Ando T, Ohmiya N, Niwa Y, Goto H (2007): Cytomegalovirus infection in severe ulcerative colitis patients undergoing continuous intravenous cyclosporine treatment in Japan. World J Gastroenterol 13, 754-760

Minami N, Yoshino T, Matsuura M, Koshikawa Y, Yamada S, Toyonaga T, Madian A, Honzawa Y, Nakase H (2015): Tacrolimus or infliximab for severe ulcerative colitis: short-term and long-term data from a retrospective observational study. BMJ Open Gastro 2, e000021

Müller A: Basics Allergologie. 1. Auflage; Urban und Fischer/Elsevier, München 2006

Nakase H, Honzawa Y, Toyonaga T, Yamada S, Minami N, Yoshino T, Matsuura M (2010): Diagnosis and Treatment of Ulcerative Colitis with Cytomegalovirus Infection: Importance of Controlling Mucosal Inflammation to Prevent Cytomegalovirus Reactivation. Dig Dis Sci $\underline{55}, 1498-1499$

Okahara K, Nagata N, Shimada T, Joya A, Hayashida T, Gatanaga H, Oka S, Sakurai T, Uemura N, Akiyama J, Spencer J (2017): Colonic cytomegalovirus detection by mucosal PCR and antiviral therapy in ulcerative colitis. PLoS One 12, e0183951

Pillet S, Williet N, Pouvaret A, Del Tedesco E, Saint-Sardos P, Pozzetto B, Roblin X (2016): Distribution of cytomegalovirus DNA load in the inflamed colon of ulcerative colitis patients. Am J Gastroenterol 111, 439-441

Pofelski J, Heluwaert F, Roblin X, Morand P, Gratacap B, Germain E, Brion J, Salon C, Bonaz B (2007): Cytomegalovirus and cryptogenic in ammatory bowel disease. Gastroenterol Clin Biol 31, 292-296

Preiß J, Bokemeyer B, Buhr H, Dignaß A, Häuser W, Hartmann F, Herrlinger K, Kaltz B, Kienle P, Kruis W, et al. (2014): Aktualisierte S3-Leitlinie - Diagnostik und Therapie des Morbus Crohn. Z Gastroenterol 52, 1431-1484 
Rahbar A, Boström L, Lagerstedt U, Magnusson I, Söderberg-Naucler C, Sundqvist V (2003): Evidence of Avtive Cytomegalovirus Infection and Increased Production of IL-6 in Tissue Specimens Obtained From Patients With Bowel Diseasees. Inflamm Bowel Dis 9, $154-161$

Rahier J, Ben-Horin S, Chowers Y, Conion C, De Munter P, Domènech E, Eliakim R, Eser A, Frater J, Gassull M, et al. (2009): European evidence-based Consensus on the prevention, diagnosis and management of oppurtunistic infections in inflammatory bowel disease. J Crohns Colitis $\underline{3}, 47-91$

Roberts E, Haan M, Dowd J, Aiello A (2010): Cytomegalovirus antibody levels, inflammation, and mortality among elderly Latinos over 9 years of follow-up. Am J Epidemiol 172, 363-371

Roblin X, Pillet S, Oussalah A, Berthelot P, Del Tedesco E, Phelip J, Chambonnière M, Garraud O, Peyrin-Biroulet L, Pozzetto B (2011): Cytomegalovirus load in inflamed tissue is predictive of resistance to immunosuppressive therapy in ulcerative colitis. Am J Gastroenterol 106, 2001-2008

Ross W, Gosh S, Dekovich A, Liu S, Ayers G, Cleary K, Lee J, Couriel D (2008): Endoscopic biopsy diagnosis of acute gastrointestinal graft-versus-host disease: rectosigmoid biopsies are more sensitive than upper gastrointestinal biopsies. Am J Gastroenterol 103, 982-989

Santos C, Brennan D, Fraser V, Olsen M (2014): Incidence, risk factors, and outcome of delayed-onset cytomegalovirus disease in a large, retrospective cohort of heart transplant recipients. Transplant Proc $\underline{46}$, 3585-3592

Shukla T, Singh S, Loftus E, Bruining D, McCurdy J (2015): Antiviral therapy in steroidrefractory ulcerative colitis with cytomegalovirus: systemic review and meta-analysis. Inflamm Bowel Dis 21, 2718-2725

Stamminger T (1997): Zytomegalievirus-Infektion nach Transplantationen: Klinische Problematik, Diagnostik und Therapie. Dtsch Ärztebl 94, A-168-173

Vilibic-Cavlek T, Kolaric B, Ljubin-Sternak S, Kos M, Kaic B, Mlinaric-Galinovic G (2015): Prevalence and dynamics of cytomegalovirus infection among patients undergoing chonic hemodialysis. Indian J Nephrol 25, 95-98

Wagner J, Vogelsang G, Beschorner W (1989): Pathogenesis and pathology of graft-vs.-host Disease. Am J Pediatr Hematol Oncol 11, 196-212

Wu J, Ma H, Lu C, Chen J, Lee P, Jou S, Yang Y, Chang H, Lu M, Chang L, Huang L (2017): Risc factors and outcomes of cytomegalovirus viremia in pediatric hematopoietic stem

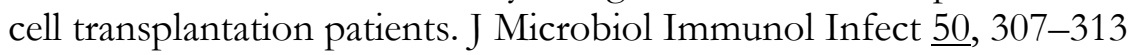

Yamada S, Yoshino T, Matsuura M, Minami N, Toyonaga T, Honzawa Y, Tsuji Y, Nakase H (2014): Long-term efficacy of infliximab for refractory ulcerative colitis: results from a single center experience. BMC Gastroenterology $\underline{14}, 80$ 
Yoshino T, Nakase H, Ueno S, Uza N, Inoue S, Mikami S, Matsuura M, Ohmori K, Sakurai T, Nagayama S, et al. (2007): Usefulness of quantitative real-time PCR assay for early detection of cytomegalovirus infection in patients with ulcerative colitis refractory to immunosuppressive therapies. Inflamm Bowel Dis $\underline{13}$, 1516-1521

Yoshino T, Nakase H, Matsuura M (2012): Letter: mucosal PCR for cytomegalovirus in refractory ulcerative colitis. Aliment Pharmacol Ther $\underline{36}, 811$ 


\section{Danksagung}

Ich bedanke mich bei meinem Doktorvater PD Dr. med. Amanzada für seine sehr gute Betreuung und für die Vergabe dieser Doktorarbeit an mich. Mein Dank gilt außerdem den Mitarbeitern des Instituts für Medizinischen Statistik der UMG für die Betreuung hinsichtlich der statistischen Analysen, ebenso den Mitarbeitern des Zentralarchivs der UMG für die Bereitstellung der Akten und die stets freundliche Kommunikation.

Ein zusätzlicher Dank geht an:

Dr. med. Eirini Mavropoulou, Annett Ternes, Victoria Eberhardt, Babette Hartmann, Daniel Laufer, Dr. med. Hartmut Fischer und Prof. Dr. med. Hans-Michael Klinger für die konstruktive Auseinandersetzung mit diesem Thema. 